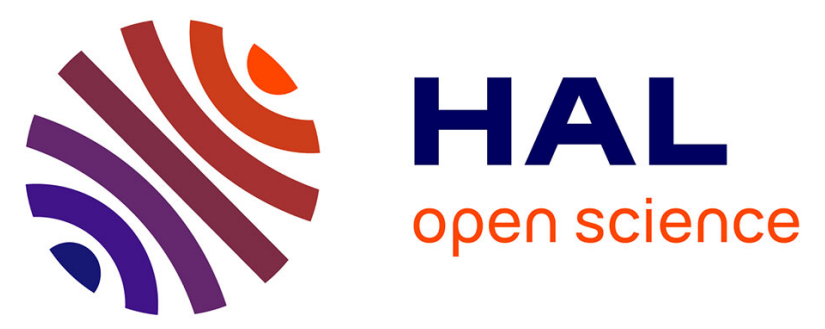

\title{
A new valorization route for Olive Mill wastewater: Improvement of durability of PP and PBS composites through multifunctional hybrid systems
}

Laura Sisti, Grazia Totaro, Annamaria Celli, Audrey Diouf-Lewis, Vincent Verney, Fabrice Leroux

\section{To cite this version:}

Laura Sisti, Grazia Totaro, Annamaria Celli, Audrey Diouf-Lewis, Vincent Verney, et al.. A new valorization route for Olive Mill wastewater: Improvement of durability of PP and PBS composites through multifunctional hybrid systems. Journal of Environmental Chemical Engineering, 2019, 7 (2), pp.103026. 10.1016/j.jece.2019.103026 . hal-02277292

\section{HAL Id: hal-02277292 \\ https://hal.science/hal-02277292}

Submitted on 20 Nov 2020

HAL is a multi-disciplinary open access archive for the deposit and dissemination of scientific research documents, whether they are published or not. The documents may come from teaching and research institutions in France or abroad, or from public or private research centers.
L'archive ouverte pluridisciplinaire HAL, est destinée au dépôt et à la diffusion de documents scientifiques de niveau recherche, publiés ou non, émanant des établissements d'enseignement et de recherche français ou étrangers, des laboratoires publics ou privés. 


\title{
A new valorization route for Olive Mill Wastewater: Improvement of durability of PP and PBS composites through multifunctional hybrid systems
}

Laura Sisti $^{1}$, Grazia Totaro* ${ }^{1}$, Annamaria Celli ${ }^{1}$, Audrey Diouf-Lewis ${ }^{2}$, Vincent Verney ${ }^{2}$, Fabrice Leroux ${ }^{2}$

${ }^{I}$ Dipartimento di Ingegneria Civile, Chimica, Ambientale e dei Materiali, Università di Bologna, Via Terracini 28, 40131 Bologna, Italy ${ }^{2}$ Institut de Chimie de Clermont Ferrand (ICCF) - UMR, CNRS, SIGMA Clermont, 6296 Université Clermont Auvergne, 24 Avenue Blaise Pascal, 63177 AUBIERE (cedex), France

* Corresponding author: Grazia Totaro - grazia.totaro@unibo.it

\begin{abstract}
Olive Mill Wastewater (OMW) is a food waste stream resulting from the production of virgin olive oil, rich in valuable natural biocompounds, such as vanillic acid, ferulic acid, protocatechuic acid, etc. In order to decrease its environmental impact and to exploit the antioxidant properties of its phenol-type molecules, OMW was intercalated into ZnAl-LDH, as well as some biomolecules composing OMW, for a general concept purpose. Such organomodified LDHs were then employed for the preparation of poly(butylene succinate) (PBS) and polypropylene (PP) composites through melt blending, to obtain materials with improved antioxidant properties and, subsequently, a better durability. A full characterization of LDHs in terms of thermal stability (TGA), morphology (XRD) and chemical modification (FT-IR) has been carried out. The composites were exposed to UV irradiation through accelerated photo-ageing and the molecular modifications were scrutinized by IR spectroscopy, revealing a strong protective role of LDH hybrid filler against oxidative process.
\end{abstract}

\section{Keywords}

Olive Mill Wastewater; multifunctional hybrid system; layered double hydroxides; durability.

\section{Introduction}

Food waste valorization, considered as energy and/or chemicals source, via biorefinery or biotechnology, gained great attention in recent years, because of the fast depletion of primary resources, increased waste generation and landfilling worldwide [1]. An aqueous offensive waste produced in huge amount in Mediterranean countries is Olive Mill Wastewater (OMW), which derives from the production of olive oil. It is characterized by high phytotoxicity and unpleasant odor. It can cause pollution of natural waters, since its illegal disposal to surface water is unfortunately still practiced $[2,3]$. Taking into account that Mediterranean countries 
produce more than 2.4 million tons per year of olives, $90 \%$ of which are is meant for olive oil production, up to 30 million $\mathrm{m}^{3}$ per year of OMW is generated: therefore, its management becomes a big issue [4-6].

The typical OMW composition includes water (83-94 wt. \%), organic compounds (4-16 wt. $\%$ ), and a minor mineral salts fraction (0.4-2.5 wt. \%), mostly composed of metals such as K, $\mathrm{Ca}$ and Na. The 2-15 wt. \% of the organic fraction are phenolic compounds such as tyrosol, hydroxytyrosol, p-coumaric acid, ferulic acid, syringic acid, protocatechuic acid, tannins, anthocyanins, catechol-melaninic polymers, etc. Due to their low partition coefficient, such compounds are more soluble in water than oil fraction. Of course, the concentration depends on the processing system but it ranges from 0.03 to $11.5 \mathrm{~g} / \mathrm{L}$. These phenolic compounds have significant bioactivity: they are natural antioxidants, for use in cosmetics, nutraceutical preparation and in agronomy [7]. Several physical, chemical and biotechnological approaches were attempted to recover biomolecules from OMW, mainly using membrane processes [810] or common extraction procedures [11]. However, the processing costs were identified as quite high.

A new simple and cost-efficient valorization route of OMW, through the preparation of multifunctional hybrid systems based on layered double hydroxides (LDHs), is investigated here. LDH structure is built of brucite-like layers with edge-sharing $\mathrm{M}(\mathrm{OH})_{6}$ octahedra $(\mathrm{M}=$ metal). The partial substitution of divalent $\mathrm{M}^{2+}$ with trivalent $\mathrm{M}^{3+}$ metals induces positive charges within the layers, counterbalanced by anions. The general LDH formula is $\left[\mathrm{M}^{2+}{ }_{1-\mathrm{x}} \mathrm{M}^{3+}{ }_{\mathrm{x}}(\mathrm{OH})_{2}\right]^{\mathrm{x+}}\left(\mathrm{A}_{\mathrm{x} / \mathrm{m}}\right)^{\mathrm{x}-} \mathrm{nH}_{2} \mathrm{O}$ where $\mathrm{A}$ is the anion. LDHs are versatile in terms of intraand interlayer composition and can be functionalized through one pot synthesis. Moreover, the relative easiness to be scaled-up, together with their biocompatibility makes LDHs materials appealing candidates for sustainable solutions. Literature reports examples of LDH modified with carboxylates, hydroxyl carboxylate, sulfate and sulfonate, amino-acids, etc. [12-18] according to the final properties desired. They are used as catalysts, anion exchangers, additives and/or stabilizers in polymer formulations, sorbents and scavengers for pollutants $[19,20]$.

In this respect, the idea is here to intercalate OMW into LDH host structures in order to decrease the environmental impact of such biowaste while exploiting the antioxidant properties of the phenol-type molecules present, such as ferulic acid, vanillic acid, protocatechuic acid, etc. Such organo-modified LDHs will then be employed as fillers in two polymer composites in order to improve their durability. Privas et al. [21] and Thompson et al. [22] reported several advantages regarding the incorporation of polyphenol-type molecules 
into LDH structures: they thermally protect the organic molecules, prevent the production of inconvenient odors thanks to the interleaving of lignosulfate molecules,-and can disguise the taste of drug molecules. Hence, the aim of the present work is to target materials that will meet multifunctionality of common sense in the applicative domains (e.g. packaging). In fact, it is well known that the organic functionalization of LDH induces a strong interaction at the interface filler/polymer through its tethered molecules, with consequent notable boosting of mechanical and barrier performances. Therefore, multifunctional materials can be achieved.

To face our concept, polypropylene (PP) and poly(butylene succinate) (PBS) are found to be of interest. Indeed, PP is one of the most important thermoplastics, commonly used for fabrics, films, bottles, sheets, automotive parts, as well as in pharmaceutical and medical device packaging and food packaging, thanks to its toughness and good chemical, fatigue and heat resistance. The stabilization of PP from oxidation has been largely reported, and is still of industrial interest to replace commonly used banned antioxidant organic molecules [23, 24]. PBS is a biodegradable polyester with adequate mechanical properties but low melt strength and viscosity, therefore its application in thermoplastic processing, in terms of foaming and filming, is limited [25]. The enhancement of its durability can widen its potential fields of application.

Other natural antioxidants used in polymeric materials are carotenoids, flavonoids and phenolic polymers such as lignin $[26,27]$ but further research is necessary to apply them routinely in polymers processing and application.

On the basis of such considerations, OMW was used as intercalating agent in ZnAl-LDH and, for comparative reasons, some model systems were also prepared by intercalating some antioxidant molecules, chosen among the ones present in OMW. The organo-modified LDHs were employed for the preparation of PBS and PP composites through classical melt blending. Physico-chemical characterizations of the resulting « green » organo-modified LDH and their state of dispersion within the associated polymer composites were investigated by FT-IR, TGA, DSC and XRD, respectively. The composite samples were then exposed to UV irradiation in an accelerated photo-ageing device and the modifications in their structures were analyzed by IR spectroscopy.

\section{Experimental}

\subsection{Materials}

Sodium hydroxide, sodium carbonate, aluminum nitrate $\mathrm{Al}\left(\mathrm{NO}_{3}\right)_{3} \cdot 9 \mathrm{H}_{2} \mathrm{O}$ (purity $\geq 98 \%$ ), zinc nitrate $\mathrm{Zn}\left(\mathrm{NO}_{3}\right)_{2} \cdot 6 \mathrm{H}_{2} \mathrm{O}$ (purity 98\%), vanillic acid (VA, purity $\geq 97 \%$ ), trans-ferulic 
acid (FA, purity 99\%), protocatechuic acid (PA, purity $\geq 97 \%$ ) and ethanol were purchased from Aldrich Chemical. All the materials were used as received. The olive mill wastewater (OMW) was supplied by Sant'Agata d'Oneglia (Imperia, Italia) and concentrated prior to use. Its main chemical features were as follows: Chemical Oxygen Demand (COD) $43.5 \pm$ $1.6 \mathrm{~g} / \mathrm{L}$; Total Organic Compound (TOC) $4.51 \pm 0.65 \mathrm{~g} \mathrm{GA}$ eq/L (GA = gallic acid); Total Suspended Solids (TSS) $39200 \pm 4808$ mg/L. PBS (Natureplast PBE003, M $_{\mathrm{w}}$ 84000, PDI 2.4) was supplied by Natureplast and PP (DM55pharm, Melt Flow Rate $\left(230{ }^{\circ} \mathrm{C} / 2,16 \mathrm{~kg}\right)$ $2,8 \mathrm{~g} / 10 \mathrm{~min}$ ) by Borealis.

\subsection{LDHs syntheses}

\subsubsection{Single Anion and Olive Mill Wastewater coprecipitation}

The coprecipitation procedure was previously reported [28]. Briefly, $50 \mathrm{~mL}$ of deionized water solution containing $31.2 \mathrm{mmol}$ of $\mathrm{Zn}\left(\mathrm{NO}_{3}\right)_{2} \cdot 6 \mathrm{H}_{2} \mathrm{O}$ and $15.6 \mathrm{mmol}$ of $\mathrm{Al}\left(\mathrm{NO}_{3}\right)_{3} \cdot 9 \mathrm{H}_{2} \mathrm{O}$ were added dropwise (flow rate $0.3 \mathrm{ml} / \mathrm{min}$ ), during $3 \mathrm{~h}$, in a reactor containing $62.4 \mathrm{mmol}$ of VA in $100 \mathrm{~mL}$ of ethanol/deionized water (60/40), under vigorous magnetic stirring. The $\mathrm{pH}$ was maintained at $9.5( \pm 0.1)$ through dropwise addition of $\mathrm{NaOH}$ solution $(100$ $\mathrm{ml}, 5 \mathrm{M})$. The reaction was carried out under nitrogen atmosphere to avoid the presence of carbonate. The suspension was stirred for $3 \mathrm{~h}$, at room temperature (around $20{ }^{\circ} \mathrm{C}$ ). The solid material was separated and submitted to 6 cycles of washing by ethanol/deionized water (3/2) centrifugation in order to eliminate the excess of VA and $\mathrm{NaOH}$. Centrifuge was set at $4500 \mathrm{rpm}$ and each cycle lasted around 20 minutes. The sample was labeled as $\mathrm{Zn}_{2} \mathrm{Al} / \mathrm{VA}$. The other LDHs were similarly prepared, with a ratio $\mathrm{Zn}^{2+} / \mathrm{Al}^{3+}=2$ and an input anion ratio $\mathrm{A}^{-} / \mathrm{Al}^{3+}=4$ during the coprecipitation, where $\mathrm{A}=\mathrm{VA}, \mathrm{FA}, \mathrm{PA}$. The products were oven-dried, overnight at $40{ }^{\circ} \mathrm{C}$. Colored powders were obtained: $\mathrm{Zn}_{2} \mathrm{Al} / \mathrm{VA}$ light caramel, $\mathrm{Zn}_{2} \mathrm{Al} / \mathrm{FA}$ light yellow, and $\mathrm{Zn}_{2} \mathrm{Al} / \mathrm{PA}$ dark brown (Figure 1).

OMW intercalated LDH was similarly prepared and the waste was previously concentrated with a rotary evaporator: from 10 liters to almost 1 liter, $60 \mathrm{ml}$ of which were used for the coprecipitation. The final product was a beige/brown powder, labeled as $\mathrm{Zn}_{2} \mathrm{Al} / \mathrm{OMW}$ (Figure 1).

A sample with carbonate was also synthesized for comparison $\left(\mathrm{Zn}_{2} \mathrm{Al} / \mathrm{C}\right)$ : metals were added dropwise, under air atmosphere, to a deionized water solution containing $\mathrm{Na}_{2} \mathrm{CO}_{3}$ [29]. The anion ratio was $\mathrm{CO}_{3}{ }^{2-} / \mathrm{Al}^{3+}=2$; after several washing in deionized water and drying in oven overnight at $40{ }^{\circ} \mathrm{C}$, a white powder was obtained.

\subsubsection{Mixed LDH systems (Double/Triple Anion co-intercalation)}


The coprecipitation procedure for the mixed systems was similar to the procedure reported above. The anion ratio was $\mathrm{A}^{-} / \mathrm{Al}^{3+}=2$ for $\mathrm{FA}$ and $\mathrm{PA}$ in $\mathrm{Zn}_{2} \mathrm{Al} / \mathrm{FA}-\mathrm{PA}$, and $\mathrm{A}^{-} / \mathrm{Al}^{3+}=1.3$ for VA, FA, PA in $\mathrm{Zn}_{2} \mathrm{Al} / \mathrm{VA}-\mathrm{FA}-\mathrm{PA}$. After washing and drying, a brown powder was obtained (Figure 1).

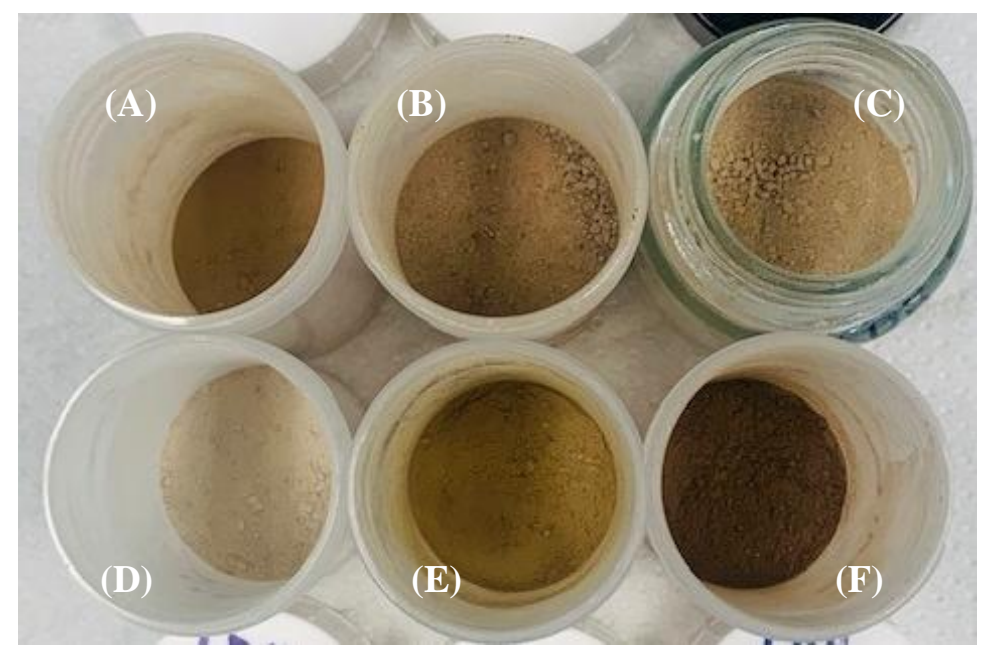

Figure 1. Image of the organo-modified LDHs: (A) $\mathrm{Zn}_{2} \mathrm{Al} / \mathrm{FA}-\mathrm{PA}$, (B) $\mathrm{Zn}_{2} \mathrm{Al} / \mathrm{VA}-\mathrm{FA}-\mathrm{PA}$, (C) $\mathrm{Zn}_{2} \mathrm{Al} / \mathrm{OMW}$, (D) $\mathrm{Zn}_{2} \mathrm{Al} / \mathrm{VA}$, (E) $\mathrm{Zn}_{2} \mathrm{Al} / \mathrm{FA} \mathrm{Zn}{ }_{2} \mathrm{Al} / \mathrm{PA}$.

\subsection{Nanocomposites preparation}

The mixture between polymer and 5 wt. \% of hybrid LDH was melt-extruded by a twin screw co-rotating extrusion using a Haake MiniLab Micro Compounder (Thermo Electron Corporation, Germany) operating at $135{ }^{\circ} \mathrm{C}$ (PBS) and $180{ }^{\circ} \mathrm{C}$ (PP) with a rotating speed of $100 \mathrm{rpm}$ for $5 \mathrm{~min}$. The samples were named PBS: $\mathrm{Zn}_{2} \mathrm{Al} / \mathrm{X}$ or PP: $\mathrm{Zn}_{2} \mathrm{Al} / \mathrm{X}$, according to the $\mathrm{LDH}$ used. References without filler were also extruded (PBS and PP).

\subsection{Accelerated photoageing procedure}

Film samples with a thickness of about $100 \mu \mathrm{m}$, were exposed to UV irradiation at $60{ }^{\circ} \mathrm{C}$ in a dry accelerated photoageing device (based on SEPAP 12/24 device) [30, 31]. This polychromatic set-up was equipped with a medium pressure mercury source filtered by borosilicate envelope (Mazda type MA 400) supplying radiation of wavelengths longer than $300 \mathrm{~nm}$. The temperature of samples was controlled at $60^{\circ} \mathrm{C}$ by a Pt probe $(\mathrm{Pt} 1000)$ in contact with a polyethylene film, connected to 3 fans on the walls of the device. Films were analyzed after various exposure times by FT-IR spectroscopy. Such approach is a rapid, mainly non-destructive and highly relevant method to study ageing processes involved in the environmental degradation of polymers, described in ISO/DIS 10640. 


\subsection{Measurements}

FT-IR analysis has been conducted on LDH samples over the wavenumber range of $650-4000 \mathrm{~cm}^{-1}$ using a Perkin Elmer Spectrum One spectrometer equipped with a Universal ATR Sampling Accessory. All the composites were analyzed from 400 to $4000 \mathrm{~cm}^{-1}$ in transmission mode by using a Thermo Scientific Nicolet 6700 FT-IR instrument. A single film was analyzed after different UV exposure times. Each spectrum was obtained from 32 scans with a resolution of $4 \mathrm{~cm}^{-1}$.

Thermogravimetric analysis (TGA) was performed in air atmosphere using a Perkin Elmer TGA7 apparatus (gas flow $30 \mathrm{ml} / \mathrm{min}$ ) at $10{ }^{\circ} \mathrm{C} \mathrm{min}{ }^{-1}$ heating rate from 50 to $900{ }^{\circ} \mathrm{C}$ for all the samples. The onset degradation temperatures $\left(\mathrm{T}_{\text {onset }}\right)$ were set at the intersection of the tangents between the initial and inflection points. The 10 and $50 \%$ mass loss temperatures $\left(\mathrm{T}^{10}{ }_{\mathrm{D}}, \mathrm{T}^{50}{ }_{\mathrm{D}}\right)$ were also measured.

The calorimetric analysis (DSC) was carried out by means of a Perkin-Elmer DSC6 under nitrogen flow. To erase any previous thermal history, the samples (ca. $10 \mathrm{mg}$ ) were first heated at $20{ }^{\circ} \mathrm{C} \min ^{-1}$ to $140{ }^{\circ} \mathrm{C}$ (PBS) or $220{ }^{\circ} \mathrm{C}$ (PP), kept at high temperature for $2 \mathrm{~min}$, and then cooled down to $-60{ }^{\circ} \mathrm{C}$ at $10^{\circ} \mathrm{C} \mathrm{min}^{-1}$. The samples were then analyzed by heating from $-60{ }^{\circ} \mathrm{C}$ to $140{ }^{\circ} \mathrm{C}$ (PBS) or $220{ }^{\circ} \mathrm{C}$ (PP) at $10^{\circ} \mathrm{C}$ $\min ^{-1}\left(2^{\text {nd }}\right.$ scan $)$. During the cooling scan the crystallization temperature $\left(T_{C}\right)$ and the enthalpy of crystallization $\left(\Delta \mathrm{H}_{\mathrm{C}}\right)$ were measured. During the $2^{\text {nd }}$ heating scan the glass transition temperature $\left(\mathrm{T}_{\mathrm{g}}\right)$, the melting temperature $\left(\mathrm{T}_{\mathrm{m}}\right)$ and the corresponding enthalpy $\left(\Delta \mathrm{H}_{\mathrm{m}}\right)$ were measured. $\mathrm{T}_{\mathrm{g}}$ was taken as the midpoint of the heat capacity increment associated with glass-to-rubber transition.

XRD measurements were carried out at room temperature with a Bragg/Brentano diffractometer XPERT-PRO with $\mathrm{Cu} \mathrm{K}_{\alpha}$ radiation $(\lambda=0.154 \mathrm{~nm}$, monochromatisation by primary graphite crystal) generated at $40 \mathrm{~mA}$ and $40 \mathrm{kV}$. Samples were measured in steps of $0.07^{\circ}$, over $2 \theta$ range of $2.2-80^{\circ}$.

TGA, XRD and FT-IR measurements were repeated 3 times, giving high reproducible data. Low molecular weight phenols (namely, gallic acid, hydroxytyrosol, 3,4hydroxybenzoic acid, tyrosol, vanillic acid, syringic acid, p-coumaric acid, ferulic acid, trans-cinnamic acid, 3-(3,4-dihydroxycinnamate) were individually analyzed via HPLC-DAD reverse phase system (Beckman Coulter, USA). Concentration of total phenols was spectrophotometrically determined on the same samples employed in HPLC analyses, by using protocatechuic acid as the analytical standard. 


\section{Results and Discussion}

\subsection{Hybrid LDH fillers}

In the present study, Olive Mill Wastewater, a biowaste rich in polyphenols, i.e. natural antioxidant molecules, was used as intercalating agent in a $\mathrm{Zn} / \mathrm{Al}$ layered double hydroxide host structures, with the aim to endow the hybrid filler with interesting properties as polymer filler. For comparative purposes, three model systems were also prepared through the intercalation of vanillic acid (VA), protocatechuic acid (PA) and trans-ferulic acid (FA), the typical chemical structures of the main components present in OMW. In addition, two mixed systems were also prepared by simultanous coprecipitation of FA, PA and VA, or just FA and PA, trying to simulate a complex medium containing more than one bioactive molecule, as in OMW.

The total organic compound (TOC) of the OMW studied was $4.51 \pm 0.65 \mathrm{~g} \mathrm{GA}$ eq/L (GA = gallic acid): this value confirms the high amount of phenols present. More specifically, HPLC analysis of OMW reveals the presence of the following phenolic compounds in order of amount (Table 1): protocatechuic acid > vanillic acid > trans-cinnamic acid > gallic acid > chlorogenic acid. 


\begin{tabular}{lcl}
\hline Phenolic Compound & Concentration in OMW $(\mu \mathrm{M})$ \\
Protocatechuic Acid & $249.3 \pm 12.8$ \\
Vanillic Acid & $70.1 \pm 5.3$ \\
trans-Cinnamic Acid & $44.1 \pm 8.0$ \\
Gallic Acid & $17.3 \pm 0.8$
\end{tabular}

Table 1: Composition of Olive Mill Wastewater (OMW).

Infrared spectroscopy was employed to check how successful the intercalation procedure was, thus providing information on the presence of phenolic anion into LDH network. ATR FT-IR spectra of the model molecules VA, FA and PA and their respective intercalated LDHs are shown in Figure 2. As can be seen the phenolic O-H stretching band is found around $3400 \mathrm{~cm}^{-1}$, while the $\mathrm{O}-\mathrm{H}$ from carboxylic group overlaps the $\mathrm{C}-\mathrm{H}$ stretching in the $3100-2980 \mathrm{~cm}^{-1}$ region. The typical $\mathrm{v}(\mathrm{C}=\mathrm{O})$ vibration is located around $1670 \mathrm{~cm}^{-1}$. Absorptions at almost 1375 and $1280 \mathrm{~cm}^{-1}$ are assigned to $\mathrm{OH}$ bending and $\mathrm{C}-\mathrm{O}$ stretching of the phenyl group, respectively. The aromatic ring bands are visible around $1595-1520 \mathrm{~cm}^{-1}$, while the sharp bands around 1050 and $750 \mathrm{~cm}^{-1}$ are assigned to the $\mathrm{C}-\mathrm{H}$ out of plane bending vibrations of benzene. The electrostatic interaction between anionic forms of VA, FA, PA and cationic LDH layers determines the splitting of carboxylic acid stretching into asymmetrical $\mathrm{v}_{\mathrm{as}}\left(\mathrm{COO}^{-}\right)$and symmetrical $\mathrm{v}_{\mathrm{s}}\left(\mathrm{COO}^{-}\right)$at around $1560 \mathrm{~cm}^{-1}$ and $1390 \mathrm{~cm}^{-1}$. When interpreting the IR spectra of the carboxylate group, the energy difference between symmetric and asymmetric stretching $\left(\Delta v_{\mathrm{a}-\mathrm{s}}\right)$ was often utilized to determine the geometry of carboxylate and its interaction with counterion. For example, 
the $\Delta v_{\mathrm{a}-\mathrm{s}}$ value was the largest when the carboxylate was unidentate to cation and it decreased in ionic state or bidentate coordination. The calculated $\Delta v_{\mathrm{a}-\mathrm{s}}$ values for $\mathrm{Zn}_{2} \mathrm{Al} / \mathrm{VA}, \mathrm{Zn}_{2} \mathrm{Al} / \mathrm{FA}, \mathrm{Zn}_{2} \mathrm{Al} / \mathrm{PA}$, are 200,193 , and $210 \mathrm{~cm}^{-1}$, fairly similar to the values obtained from the corresponding salts, revealing that the anions moieties were electrostatically stabilized in ionic form $[32,33]$. Shifts of $\mathrm{C}=\mathrm{C}, \mathrm{C}-\mathrm{O}$ stretching vibrations of the aromatic ring, as well as the aromatic $\mathrm{C}-\mathrm{H}$ out of plane, are also visible in LDHs profiles. Moreover, the $\mathrm{O}-\mathrm{H}$ vibrations from layer hydroxyl groups and interlayer water are visible at $3480 \mathrm{~cm}^{-1}$ (Figure 2a, 2c, 2e). Such spectra are consistent with previously reported infrared spectra of VA and FA intercalated LDHs [32, 34, 35].

Concerning the mixed systems $\mathrm{Zn}_{2} \mathrm{Al} / \mathrm{FA}-\mathrm{PA}$ and $\mathrm{Zn}_{2} \mathrm{Al} / \mathrm{VA}-\mathrm{FA}-\mathrm{PA}$, IR spectra are difficult to disentangle. However, three main vibration bands are pronounced, around 1370,1270 , and $800 \mathrm{~cm}^{-1}$, which probably result from more than one functional group. Even if the FT-IR spectrum of OMW may at the first glance be compared to VA-FA-PA, the IR absorption bands do not superimpose (Figure 3). $\mathrm{Zn}_{2} \mathrm{Al} / \mathrm{OMW}$ has been compared to pristine OMW solution and a powder was obtained from its direct filtration. The $\mathrm{Zn}_{2} \mathrm{Al} / \mathrm{OMW}$ IR absorption profile (Figure 3c-3d) presents broad bands (around 1600, 1380 and $1100 \mathrm{~cm}^{-1}$ ) preventing any possible assignment. However, the shift in absorption bands and the absence of other bands compared to the OMW solution (broad bands at $3300, \approx 1680,1140,1020,870 \mathrm{~cm}^{-1}$ ) and its precipitate (bands at 3300, 2930-2850, 1710, 1630, 1160, 1030, $870 \mathrm{~cm}^{-1}$ ), suggest a selective interaction with some molecules. The latter observation underlines the fact that LDH is acting as a molecular sieves retaining molecules in strong interaction with LDH platelets. Such chemical speciation may be of interest to isolate molecules. The absorption centered at approximately $3380 \mathrm{~cm}^{-1}$, indicates the stretching frequency mode of $\mathrm{O}-\mathrm{H}$ groups in the brucite-like layer, interlayer water and phenolic groups. The bands ascribed to the lattice vibration modes of $\mathrm{M}-\mathrm{O}$ and $\mathrm{O}-\mathrm{M}-\mathrm{O}$ are clearly visible in all LDH sample profiles, at low wavenumbers. So infrared spectroscopy confirms the organo-modification of all the LDHs prepared. 

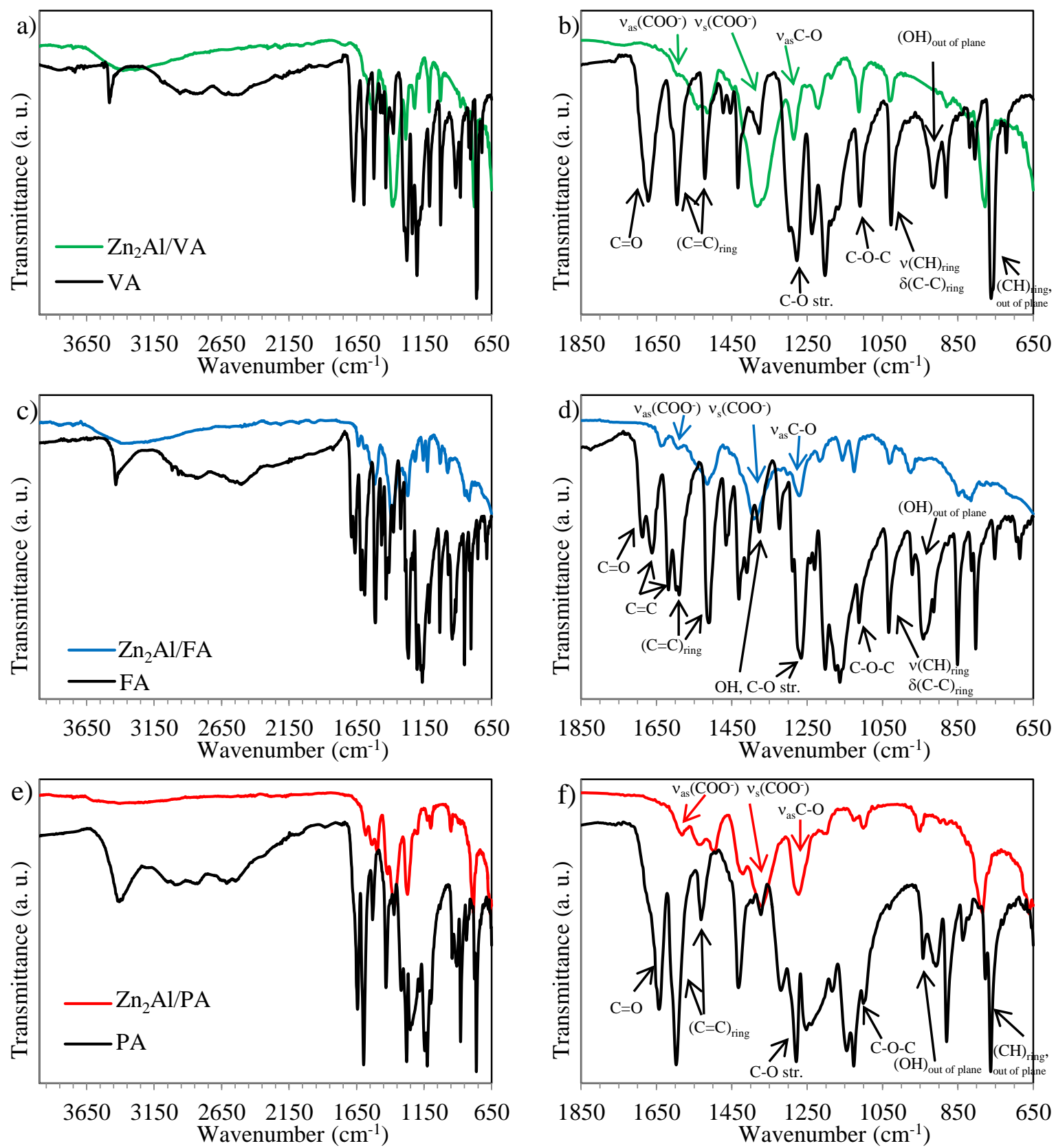

Figure 2. FT-IR of the organo-modified LDHs with VA, FA, PA, compared to the pristine molecules (left side), zoom region on the right side. 

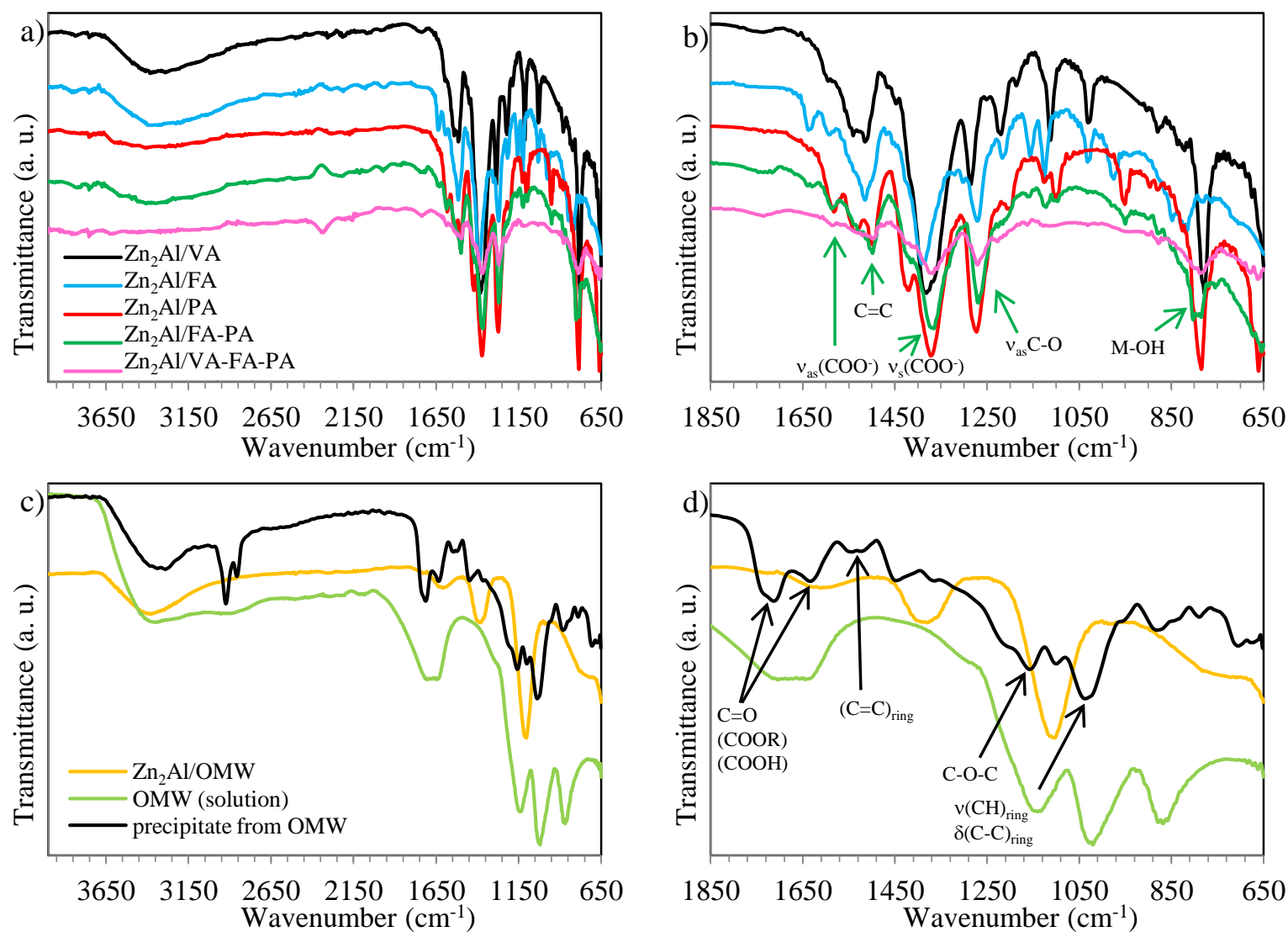

Figure 3. FT-IR of the mixed systems compared to the single molecule intercalated LDHs, $\mathrm{Zn}_{2} \mathrm{Al} / \mathrm{OMW}$ compared to OMW solution and its precipitate (left side), zoom region on the right side.

\begin{tabular}{lcccccccc}
\hline Code & $\begin{array}{c}\text { Interlayer } \\
\text { distance } \\
c^{\prime}=\mathrm{d}_{003}(\AA)^{\mathrm{a}}\end{array}$ & $\begin{array}{c}c=3 c^{\prime} \\
(\AA)^{\mathrm{b}}\end{array}$ & $\begin{array}{c}\mathrm{d}_{110} \\
(\AA)^{\mathrm{c}}\end{array}$ & $\begin{array}{c}a=2 \mathrm{~d}_{110} \\
(\AA)^{\mathrm{d}}\end{array}$ & $\begin{array}{c}\mathrm{M}^{\mathrm{II}} / \mathrm{M}^{\mathrm{III}} \\
\mathrm{Ratio}^{\mathrm{e}}\end{array}$ & $\begin{array}{c}\mathrm{A} / \mathrm{M}^{\mathrm{III}} \\
\text { Ratio }^{\mathrm{e}}\end{array}$ & $\begin{array}{c}\mathrm{T}^{10} \mathrm{D} \\
\left({ }^{\circ} \mathrm{C}\right)^{\mathrm{f}}\end{array}$ & $\begin{array}{c}\text { Residue } \\
(\%)^{\mathrm{f}}\end{array}$ \\
\hline $\mathrm{Zn}_{2} \mathrm{Al} / \mathrm{C}$ & 7.5 & 22.5 & 1.53 & 3.06 & 2.00 & n.d. & 202 & 66 \\
$\mathrm{Zn}_{2} \mathrm{Al} / \mathrm{VA}$ & 21.0 & 63.0 & 1.52 & 3.04 & 2.00 & 4.00 & 269 & 35 \\
$\mathrm{Zn}_{2} \mathrm{Al} / \mathrm{FA}$ & 17.7 & 53.1 & 1.52 & 3.04 & 2.00 & 4.00 & 253 & 39 \\
$\mathrm{Zn}_{2} \mathrm{Al} / \mathrm{PA}$ & 16.5 & 49.5 & 1.55 & 3.10 & 2.00 & 4.00 & 319 & 54 \\
$\mathrm{Zn}_{2} \mathrm{Al} / \mathrm{FA}-\mathrm{PA}$ & 14.4 & 43.2 & 1.54 & 3.08 & 2.00 & 2.00 & 287 & 52 \\
$\mathrm{Zn}_{2} \mathrm{Al} / \mathrm{VA}-\mathrm{FA}-\mathrm{PA}$ & 11.2 & 33.6 & 1.53 & 3.06 & 2.00 & 1.30 & 291 & 48 \\
$\mathrm{Zn}_{2} \mathrm{Al} / \mathrm{OMW}$ & 11.0 & 33.0 & 1.52 & 3.04 & 2.00 & n.d. & 288 & 78 \\
\hline
\end{tabular}

a $c$ ' is determined by the $(003)$ reflection;

${ }^{\mathrm{b}} \mathrm{c}$ is the total thickness of the brucite-like layers and the interlayer distance;

${ }^{c}$ Determined by the (110) reflection;

${ }^{\mathrm{d}} a$ (lattice parameter) is related to the cation-cation distance;

${ }^{\mathrm{e}}$ Metal cations ratio and anion ratio charged during the syntheses;

${ }^{\mathrm{f}}$ Determined by TGA under air flow, at $10{ }^{\circ} \mathrm{C} \mathrm{min}^{-1}$.

Table 2: Cell parameters and thermal data of the organo-modified LDHs. 
Figure 4 displays the X-ray patterns of an $\mathrm{LDH}$ carbonate $\left(\mathrm{Zn}_{2} \mathrm{Al} / \mathrm{C}\right.$, Miller indices are indicated) and of all the hybrid LDHs. Structurally, LDH structure is usually described in R-3m rhombohedral symmetry, showing the presence of harmonic peaks $(00 l)$ at lower angles and the (110) diffraction line close to $60^{\circ}$ providing interlamellar and intralamellar information, respectively. For the hybrid LDH materials, the molecule size of the sequestrated anion and their associated accommodation within the interlayer gallery can be extrapolated from $\mathrm{d}_{003}$ [36] and resulted to be 21.0, 17.7, $16.5 \AA$ for $\mathrm{Zn}_{2} \mathrm{Al} / \mathrm{VA}, \mathrm{Zn}_{2} \mathrm{Al} / \mathrm{FA}$, $\mathrm{Zn}_{2} \mathrm{Al} / \mathrm{PA}$ respectively (Table 2). Concerning FA, Kang et al. [35] reported a d-value of approximately $17.2 \AA$ and hypothesized, as possible interlayer molecular arrangement of FA between LDH layers, a perpendicular packing in a zig-zag manner with alternating phenol-acrylate $\pi-\pi$ interaction. This is here consistent with $\mathrm{Zn}_{2} \mathrm{Al} / \mathrm{FA}$ and most probably a similar accommodation is present for $\mathrm{Zn}_{2} \mathrm{Al} / \mathrm{PA}$ as well. Similar systems reported in literature could confirm such a type of accommodation $[16,28]$. Concerning $\mathrm{Zn}_{2} \mathrm{Al} / \mathrm{VA}$, by considering $8.3 \AA$ as the length of VA [34], and $4.8 \AA$ the size of the brucite-like layer, an anion bilayer arrangement may be surmised.

The X-ray profiles of the mixed systems $\mathrm{Zn}_{2} \mathrm{Al} / \mathrm{FA}-\mathrm{PA}$ and $\mathrm{Zn}_{2} \mathrm{Al} / \mathrm{VA}-\mathrm{FA}-\mathrm{PA}$, as well as $\mathrm{Zn}_{2} \mathrm{Al} / \mathrm{OMW}$, exhibit a broad halo at low angles, thus suggesting- that the number of stacked platelets should be low, i.e. small coherence size along the stacking direction making it difficult to address the nature of the interleaved anions. Additional sharp diffraction peaks are observed for most of the hybrid LDH phase and are even more pronounced in the case of $\mathrm{Zn}_{2} \mathrm{Al} / \mathrm{OMW}$, where two different contaminations seem to be present. More in detail, the reflections at $18,28,34,48,54,56^{\circ}$ (marked with $*$ in Figure 4) can probably refer to boehmite. Yang et al. [37] indeed reported the transformation mechanism of the typical MgAl-LDH and revealed that, at the first stage of the synthesis, amorphous colloidal hydroxide aluminum is formed from the aluminum precursor salt solution. Then, the amorphous hydroxides are transformed into the crystallites of oxidehydroxide aluminum boehmite $\gamma$-AlOOH. Therefore, it would mean that the coprecipitation of LDH in presence of OMW is not $100 \%$ efficient in yielding LDH structure. The reflections at $32,39^{\circ}$ (marked with ${ }^{\circ}$ in Figure 4) are ascribable to a nonspecific organic/inorganic salt. In order to identify such salt, the powder obtained from the direct filtration of OMW has been also analysed, and it was found out that the only crystalline component probably present is $\mathrm{CaSO}_{4}$ (profile not shown). In any case, such considerations may explain the smaller amount of organic in that hybrid (found by TGA and discussed below) taking into account the formation of another inorganic material $(\gamma$ - 
$\mathrm{AlOOH})$ unable to trap organic guests. It is interesting to highlight that both the mixed system $\mathrm{Zn}_{2} \mathrm{Al} / \mathrm{VA}-\mathrm{FA}-\mathrm{PA}$ and $\mathrm{Zn}_{2} \mathrm{Al} / \mathrm{OMW}$ feature a close interlayer distance, namely 11 $\AA$. This suggests a similar arrangement of the guest anions.

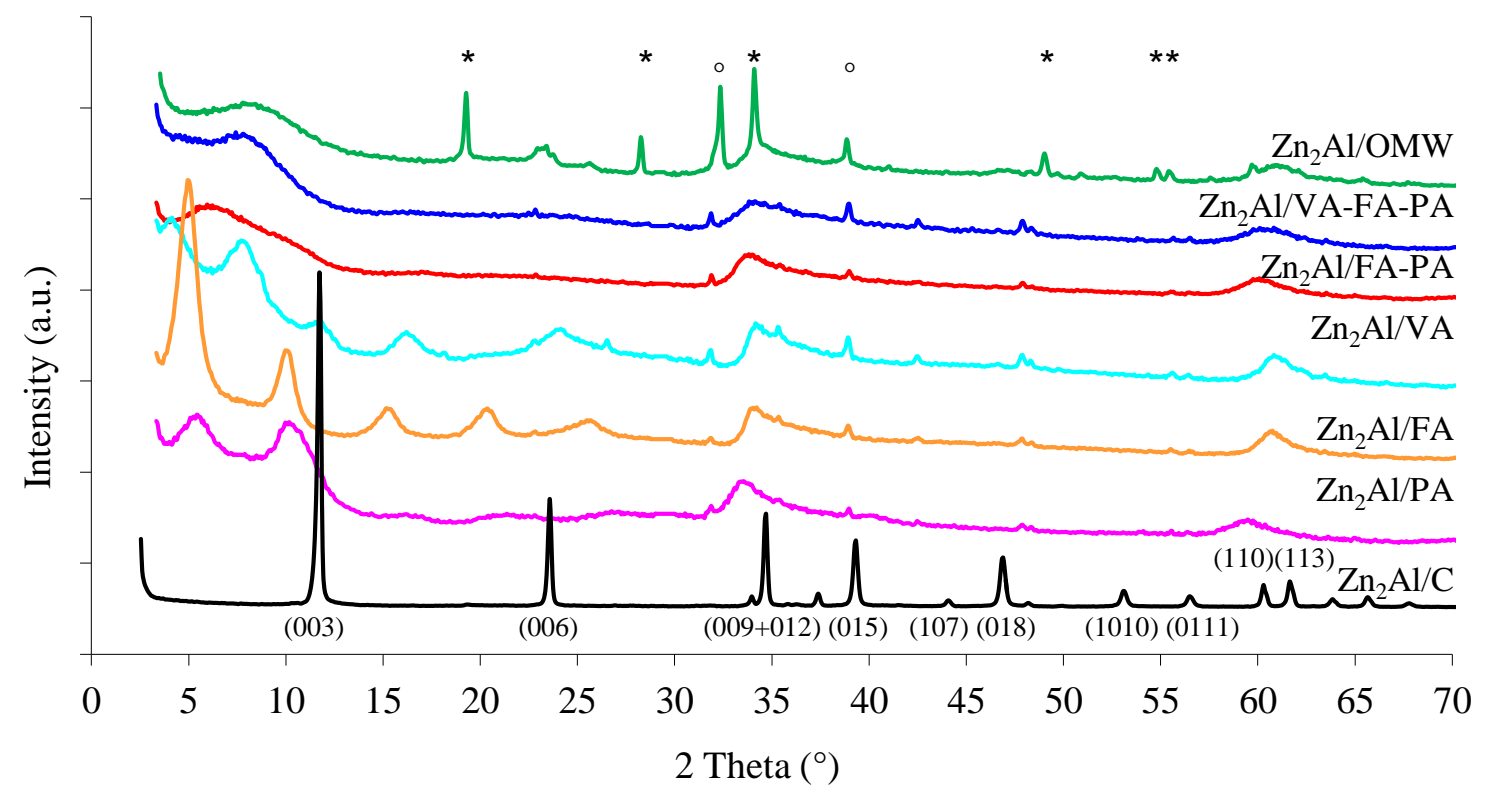

Figure 4: XRD profiles of as-prepared hybrid LDHs. Miller indices are indicated for LDH carbonate (* possible boehmite $\gamma-\mathrm{AlOOH} ;{ }^{\circ}$ non-specific organic/inorganic salt).

The results of the thermogravimetric analysis are reported in Table 2 while the thermogravimetric profiles are visible in Figures 5-6. The degradation occurs in three main stages for VA, PA and FA. The corresponding LDHs show three main weight losses as well as the corresponding mixed systems and $\mathrm{Zn}_{2} \mathrm{Al} / \mathrm{C}$ (as reference), which displays the typical profile for such LDH type [16]. Adsorbed and interlayer water lose weight at the first step. The succeeding degradation stages correspond to the competitive dehydroxylation of the layers and to the decomposition of the intercalated carbonate or antioxidant species that is evidenced in both the $\mathrm{Zn}_{2} \mathrm{Al} / \mathrm{C}$ and the synthesized hybrid samples, respectively. The residue consists of mixed metal oxides. The total mass loss, which gives an indication of the organic content, is low for $\mathrm{Zn}_{2} \mathrm{Al} / \mathrm{OMW}(22 \%)$. On the other hand all the other LDHs have higher total mass losses around 50/60 wt. \% (Table 2). This is consistent with the concomitant formation, for $\mathrm{Zn}_{2} \mathrm{Al} / \mathrm{OMW}$, of another inorganic material, unable to trap the organic guest, as previously discussed, as well as a possible poorer "anion"/Al ratio, respect to other samples. As far as thermal stability is concerned, in terms of $\mathrm{T}^{10}$, the order is $\mathrm{Zn}_{2} \mathrm{Al} / \mathrm{PA}>\mathrm{Zn}_{2} \mathrm{Al} / \mathrm{VA}-\mathrm{FA}-\mathrm{PA}>\mathrm{Zn}_{2} \mathrm{Al} / \mathrm{OMW}>\mathrm{Zn}_{2} \mathrm{Al} / \mathrm{FA}$ $\mathrm{PA}>\mathrm{Zn}_{2} \mathrm{Al} / \mathrm{VA}>\mathrm{Zn}_{2} \mathrm{Al} / \mathrm{FA}>\mathrm{Zn}_{2} \mathrm{Al} / \mathrm{C}$. 
By observing the TGA profiles (Figure 5) of the single molecule intercalated LDHs, it is evident a shift to higher temperatures respect to the profiles corresponding to the pristine molecules VA, FA, PA: therefore, as As expected, the LDH structure has a thermoprotective role against the biomolecules, enhancing their thermal stability. This allows the persistence of the bioactivity in $\mathrm{LDH}$ and, in turn, into the polymer formulations.

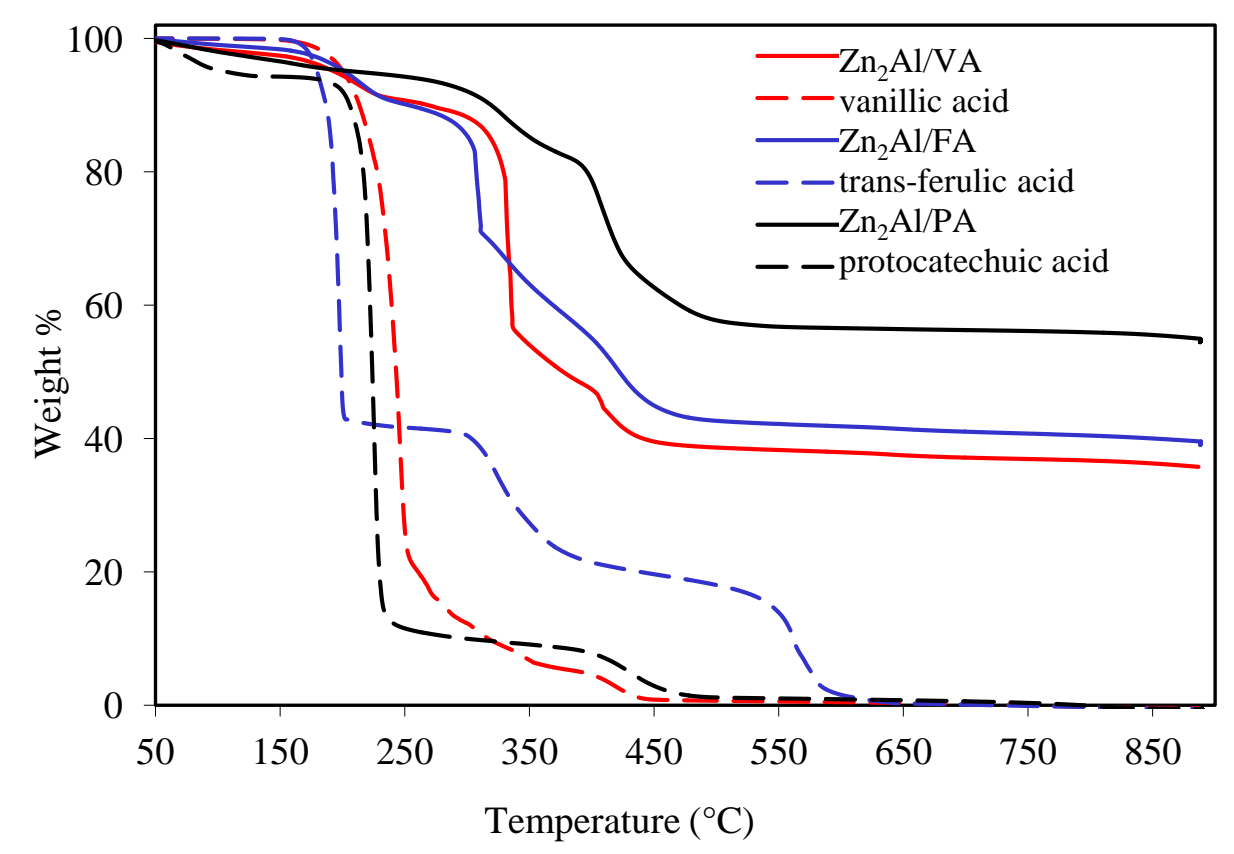

Figure 5: TGA profiles of the single molecule intercalated LDHs (straight lines) compared to pristine organic molecules (dashed lines): vanillic acid, trans-ferulic acid and protocatechuic acid. 


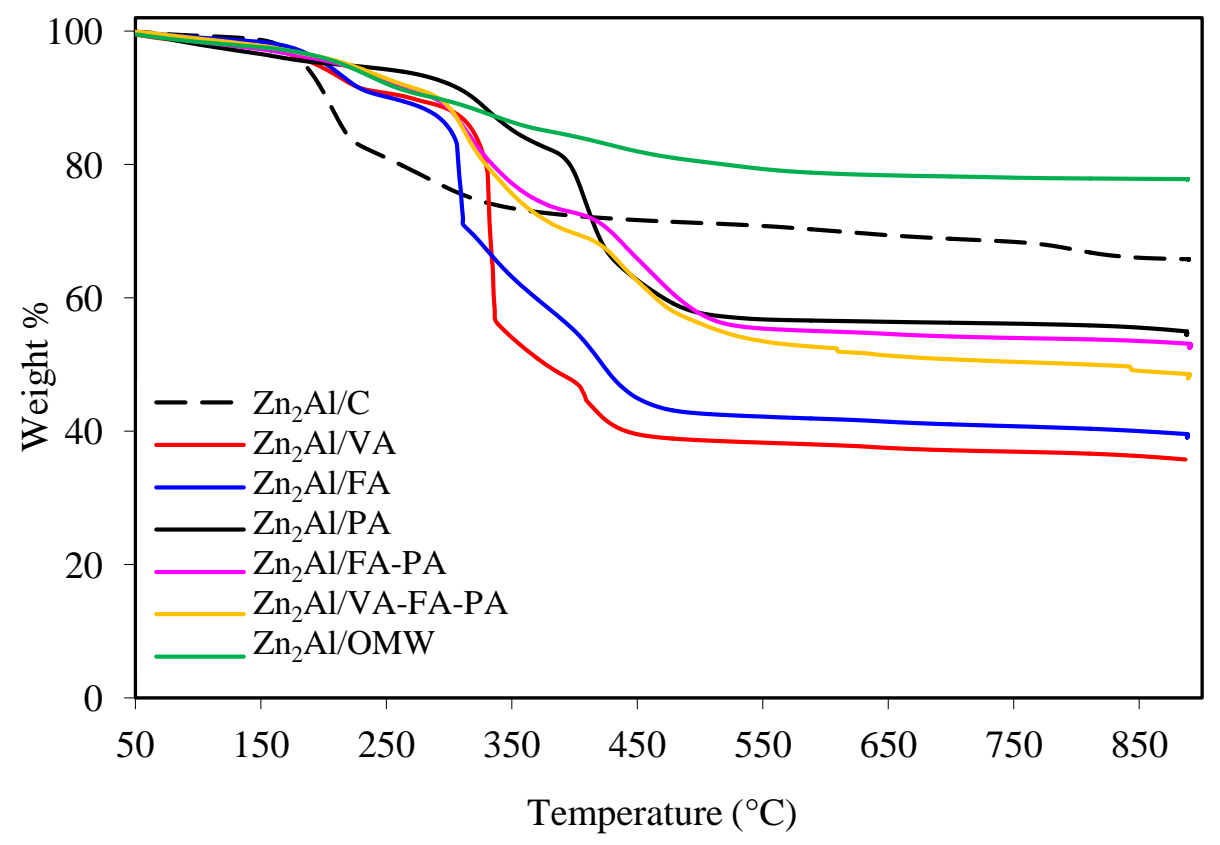

Figure 6: TGA profiles of all the LDHs prepared together with $\mathrm{Zn}_{2} \mathrm{Al} / \mathrm{C}$ as reference.

\subsection{Nanocomposites}

The organo-modified LDHs have been dispersed into PBS and PP by melt blending, in order to enhance their antioxidant performances. An amount of $5 \mathrm{wt}$ \% of filler was used according to a previous study reporting this to be suitable to maintain the UV-stability of similar antioxidant molecules in PBS composites [38]. The melt-blending procedure, already described in previous papers $[14,16]$, proves to be an effective method to reach an adequate filler dispersion. The degree of dispersion of the organo-modified LDHs in both matrices was evaluated by XRD analysis (Figures 7-8).

PBS composites (Figure 7) show the diffraction peaks at $2 \theta=19.7,22.0$, and $22.9^{\circ}$ assigned to (020), (021), and (110) planes of PBS $\alpha$ crystals [39]. Then, according to literature, LDH does not substantially modify the crystalline phase of PBS [40]. PBS: $\mathrm{Zn}_{2} \mathrm{Al} / \mathrm{FA}$ presents a small reflection around $5^{\circ}$, ascribable to the pristine $\mathrm{Zn}{ }_{2} \mathrm{Al} / \mathrm{FA}$ clay while all the other traces do not show reflections at low angles. Therefore, an exfoliation process had probably occurred in all samples, with the exception of $\mathrm{PBS}: \mathrm{Zn}_{2} \mathrm{Al} / \mathrm{FA}$, where an intercalated system is still depicted. 


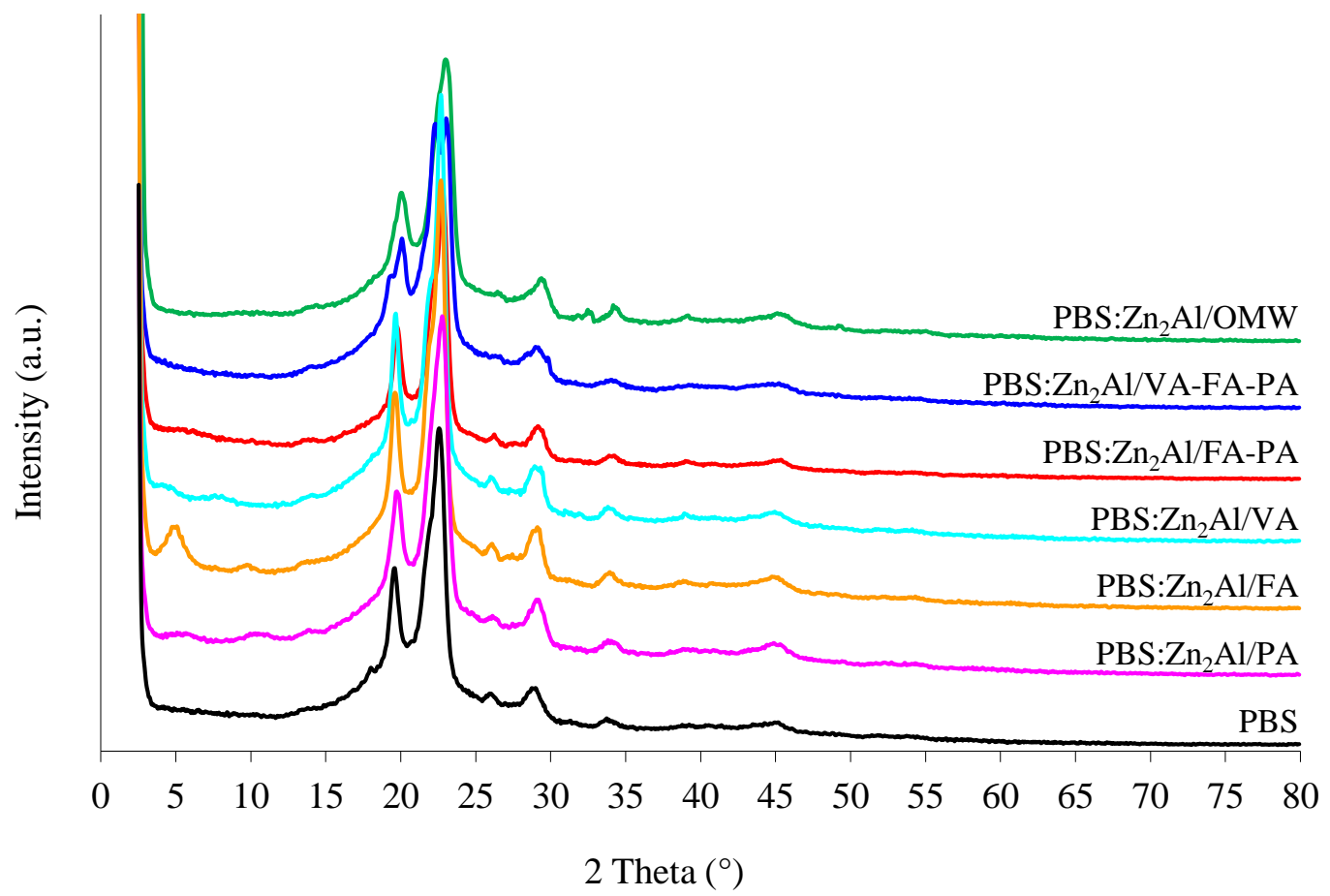

Figure 7: XRD profiles of PBS and its composites.

Concerning PP composites (Figure 8), no diffraction lines at low $2 \theta$ angles, ascribable to the pristine filler, are visible, suggesting the possible achievement of an exfoliation state. The diffraction lines for $\alpha$-PP were observed at $2 \theta=14.1,16.9,18.5,21.1$ and $21.8^{\circ}$, corresponding to the reflection planes (110), (040), (130), (111) and (041), respectively, of the $\alpha$-monoclinic PP structure [41] (Figure 8b). A reflection was observed at about $2 \theta=$ $16.0^{\circ}$ in PP homopolymer, corresponding to the (300) plane of the $\beta$ form of PP, which presents a trigonal structure $[12,42]$. In almost all composites, such $\beta$-phase assigned $(h k l)$ of (300) is more pronounced. Therefore, LDHs platelets seem to partially convert the structural organization of PP from $\alpha$ to $\beta$-phase. These findings are in agreement with Leroux et al. [12], who found that $\beta$-phase in polypropylene was promoted by developing an interfacial attrition, due the modified LDH and hence the generation of $\beta$-phase crystals during composite formation. The formation of $\beta$-phase crystals has implications leading to higher impact strengths [43]. Moyo et al. also observed that LDH promotes $\beta$-phase nucleation in PP [42]. 

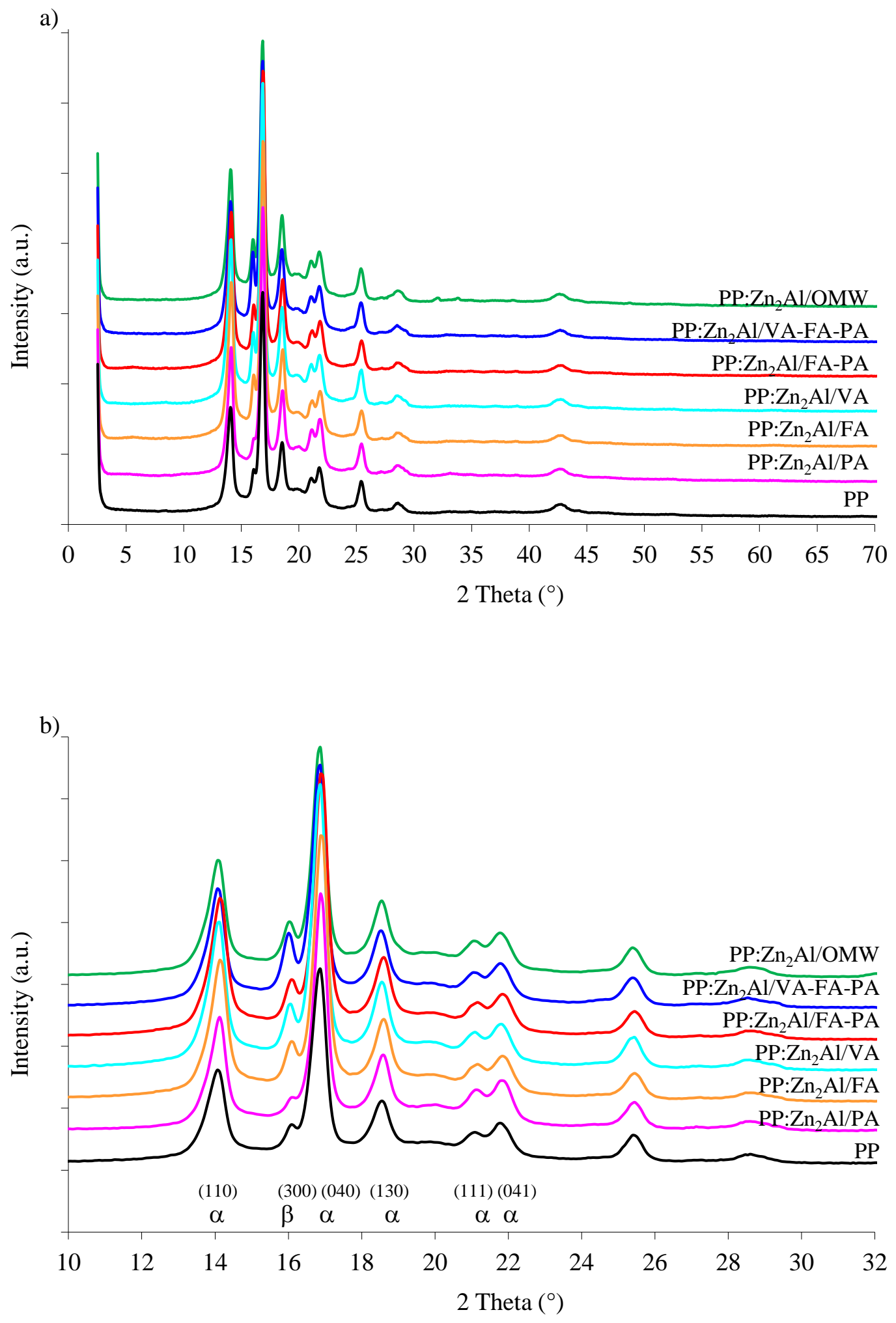

Figure 8: XRD profiles of PP and its composites a) and zoom region b).

Concerning the calorimetric data, the melting temperatures of both series of samples remain fairly constant, namely around $115^{\circ} \mathrm{C}$ for PBS and $164{ }^{\circ} \mathrm{C}$ for PP nanocomposites 
(Table 3). No significant differences are related to the crystallization temperatures in PBS, while in PP samples some composites crystallize at a slightly higher temperature, indicating a moderate nucleating effect of the filler toward the matrix. In both series a decrease in enthalpy values seems to be present in almost all composites with respect to PBS and PP, thus highlighting a slight hindering effect of the LDH. Considering the glass transition temperature of all samples, a small decrease of its value might indicate that the presence of the rigid nanosheets of fillers causes an increment of the free volume.

TGA thermograms and data are reported in ESI (Figures S1-S2) and Table 3, respectively. The thermal stability of PBS, as already reported in previous papers $[16,17]$, is not improved by LDH because the metals can catalyze the intermolecular and intramolecular transesterifications and the water released can cause chain hydrolysis. On the other hand, LDH improves the thermal stability of PP, as observed by TGA curves (Figure S4), $\mathrm{T}_{\text {onset }}$ and $\mathrm{T}^{50}{ }_{\mathrm{D}}$ values reported in Table 3 . In particular, $\mathrm{T}^{50}{ }_{\mathrm{D}}$ values are higher as compared to PP, consistently with previous findings [42, 44, 45]. A more detailed description is reported in ESI.

\begin{tabular}{|c|c|c|c|c|c|c|c|c|}
\hline Sample & $\begin{array}{c}\mathrm{T}_{\mathrm{g}} \\
\left({ }^{\circ} \mathrm{C}\right)^{\mathrm{a}}\end{array}$ & $\begin{array}{c}\mathrm{T}_{\mathrm{C}} \\
\left({ }^{\circ} \mathrm{C}\right)^{\mathrm{b}}\end{array}$ & $\begin{array}{l}\Delta \mathrm{H}_{\mathrm{C}} \\
(\mathrm{J} / \mathrm{g})^{\mathrm{b}}\end{array}$ & $\begin{array}{c}\mathrm{T}_{\mathrm{m}} \\
\left({ }^{\circ} \mathrm{C}\right)^{\mathrm{a}}\end{array}$ & $\begin{array}{l}\Delta \mathrm{H}_{\mathrm{m}} \\
(\mathrm{J} / \mathrm{g})^{\mathrm{a}}\end{array}$ & $\begin{array}{l}\mathrm{T}_{\text {onset }} \\
\left({ }^{\circ} \mathrm{C}\right)^{\mathrm{c}}\end{array}$ & $\begin{array}{l}\mathrm{T}^{50} \mathrm{D} \\
\left({ }^{\circ} \mathrm{C}\right)^{\mathrm{c}}\end{array}$ & $\begin{array}{c}\text { Residue } \\
(\%)^{\mathrm{c}}\end{array}$ \\
\hline PBS & -29 & 85 & 63 & 115 & 51 & 381 & 400 & 0.0 \\
\hline $\mathrm{PBS}: \mathrm{Zn}_{2} \mathrm{Al} / \mathrm{VA}$ & -29 & 84 & 53 & 116 & 44 & 367 & 387 & 2.4 \\
\hline $\mathrm{PBS}: \mathrm{Zn}_{2} \mathrm{Al} / \mathrm{FA}$ & -30 & 84 & 62 & 116 & 51 & 349 & 385 & 2.7 \\
\hline $\mathrm{PBS}: \mathrm{Zn}_{2} \mathrm{Al} / \mathrm{PA}$ & -30 & 85 & 60 & 117 & 52 & 373 & 395 & 2.3 \\
\hline PBS:Zn ${ }_{2} \mathrm{Al} / \mathrm{FA}-\mathrm{PA}$ & -32 & 85 & 59 & 116 & 49 & 367 & 389 & 3.1 \\
\hline PBS:Zn ${ }_{2} \mathrm{Al} / \mathrm{VA}-\mathrm{FA}-\mathrm{PA}$ & -31 & 85 & 59 & 116 & 45 & 365 & 388 & 3.0 \\
\hline $\mathrm{PBS}: \mathrm{Zn}_{2} \mathrm{Al} / \mathrm{OMW}$ & -31 & 85 & 58 & 116 & 45 & 363 & 385 & 4.7 \\
\hline $\mathrm{PP}$ & -3 & 115 & 77 & 164 & 61 & 301 & 336 & 0.0 \\
\hline $\mathrm{PP}: \mathrm{Zn}_{2} \mathrm{Al} / \mathrm{VA}$ & -5 & 119 & 74 & 164 & 59 & 288 & 345 & 0.2 \\
\hline $\mathrm{PP}: \mathrm{Zn}_{2} \mathrm{Al} / \mathrm{FA}$ & -6 & 118 & 75 & 164 & 59 & 317 & 360 & 0.9 \\
\hline $\mathrm{PP}: \mathrm{Zn}_{2} \mathrm{Al} / \mathrm{PA}$ & -4 & 116 & 77 & 164 & 58 & 310 & 363 & 1.5 \\
\hline $\mathrm{PP}: \mathrm{Zn}_{2} \mathrm{Al} / \mathrm{FA}-\mathrm{PA}$ & -5 & 117 & 74 & 164 & 54 & 313 & 359 & 1.6 \\
\hline $\mathrm{PP}: \mathrm{Zn}_{2} \mathrm{Al} / \mathrm{VA}-\mathrm{FA}-\mathrm{PA}$ & -5 & 115 & 69 & 164 & 51 & 278 & 339 & 1.1 \\
\hline $\mathrm{PP}: \mathrm{Zn}_{2} \mathrm{Al} / \mathrm{OMW}$ & -4 & 115 & 74 & 164 & 55 & 307 & 348 & 2.3 \\
\hline
\end{tabular}

${ }^{\text {a }}$ Determined by DSC during the $2^{\text {nd }}$ heating scan;

${ }^{\mathrm{b}}$ Determined by DSC during the cooling scan from the melt at $10{ }^{\circ} \mathrm{C} \mathrm{min}^{-1}$;

${ }^{\mathrm{c}}$ Determined by TGA under air flow, at $10^{\circ} \mathrm{C} \mathrm{min}^{-1}$.

Table 3: DSC and TGA results of PBS, PP and composites. 


\subsection{Durability of nanocomposites}

To investigate the durability of the polymer composites, their films were submitted to accelerated photoageing experiments in SEPAP device. Three time-resolved processes occur in PBS during photooxidation: a) oxidation of the alcoholic end groups, leading to oligomers with carboxyl chain ends; b) the hydroperoxides formed by R-H abstraction undergo thermal degradation to produce different oligomers; c) Norrish I chain cleavage reaction, which generates specific oxidation products [46]. The chemical modifications taking place under photoageing can be evaluated by transmission IR spectroscopy because of the significant changes in the two vibration zones around $1710 \mathrm{~cm}^{-1}$ and $3500 \mathrm{~cm}^{-1}$, where carbonylated and hydroxylated species absorb, respectively. Such bands can be quantitatively related to the amount of oxidation $[47,48]$. Because of the high content of ester groups in PBS, the hydroxyl band $\left(3500 \mathrm{~cm}^{-1}\right)$ is taken into account as a mark of photooxidation products formation and in Figure 9 the kinetic curves, displaying the evolution of hydroxyl absorbance as a function of photoageing time, are shown. A significant delay of the induction period is visible in composites traces respect to PBS, as well as a slowing-down of the growing trace as a function of ageing time. Indeed, the level of oxidation in composites starts to increase after 150 hours of UV exposure. This clearly demonstrates a protective role of all hybrid LDHs towards PBS. It is notable that the level of oxidation after $300 \mathrm{~h}$, as measured through an increase in the products formation, so inversely in a stability ranging as: $\mathrm{PBS}<\mathrm{PBS}: \mathrm{Zn}_{2} \mathrm{Al} / \mathrm{OMW}<\mathrm{PBS}: \mathrm{Zn}_{2} \mathrm{Al} / \mathrm{FA}<$ PBS: $: \mathrm{n}_{2} \mathrm{Al} / \mathrm{VA}-\mathrm{FA}-\mathrm{PA}<\mathrm{PBS}: \mathrm{Zn}_{2} \mathrm{Al} / \mathrm{VA}<\mathrm{PBS}: \mathrm{Zn}_{2} \mathrm{Al} / \mathrm{FA}-\mathrm{PA} \approx \mathrm{PBS}: \mathrm{Zn}_{2} \mathrm{Al} / \mathrm{PA}$. The above series can be accounted as the oxidative sensitivity sequence for PBS samples.

Similar conclusions can be carried out for PP samples. The first step of its photooxidation mechanism is the formation of hydroperoxides, which can decompose to produce alkoxy radicals. Such radicals can abstract a hydrogen on the polymeric backbone or undergo a $\beta$ scission, producing alcohols, ketones and a macro-radical. The macro-radical undergoes to further oxidation: carboxylic acids and some other carbonylated products are formed [49]. Figure 10 plots the kinetic curves of carbonylated photo-products, and the protective role exerted by LDH towards PP is clear. The homopolymer indeed starts to degrade almost immediately, without an induction period and the growing of carbonylated photo-products is fast. On the other hand, the level of oxidation in composites starts to increase after $80 \mathrm{~h}$ of UV exposure and the growing is slower respect to PP: It is interesting to note that the level of oxidation after $160 \mathrm{~h}$, measured through the products formation, increases according to the same order with respect to PBS samples so inversely in a stability ranging 
as: $\mathrm{PP}<\mathrm{PP}: \mathrm{Zn}_{2} \mathrm{Al} / \mathrm{OMW}<\mathrm{PP}: \mathrm{Zn}_{2} \mathrm{Al} / \mathrm{FA} \approx \mathrm{PP}: \mathrm{Zn}_{2} \mathrm{Al} / \mathrm{VA}-\mathrm{FA}-\mathrm{PA}<\mathrm{PP}: \mathrm{Zn}_{2} \mathrm{Al} / \mathrm{VA}<$ $\mathrm{PP}: \mathrm{Zn}_{2} \mathrm{Al} / \mathrm{FA}-\mathrm{PA}<\mathrm{PP}: \mathrm{Zn}_{2} \mathrm{Al} / \mathrm{PA}$.

In both cases, the polymer free of filler degrades more rapidly and the organo-modifying agent PA provides the better behavior, alone or combined with FA, while VA seems to be not suitable, alone or combined with FA and PA. The latter observation for the mixture VA-FA-PA is consistent with the results gathered for PP: $\mathrm{Zn}_{2} \mathrm{Al} / \mathrm{OMW}$.

The antioxidant activity of polyphenols is due to the hydrogen atom transfer from the phenolic hydroxyl group to the reacting radical. The activity is affected by the number and position of phenolic $\mathrm{OH}$ groups and the presence of substituents, because they affect the energy barrier required for $\mathrm{H}$ abstraction. The energy barrier significantly decreases with the increase in number of hydroxyl groups if they are in the orto-position, while the effect of additional hydroxyl groups is smaller, if they are located in the para- and meta-positions. This can be the reason of the better perfomances of PA [26].

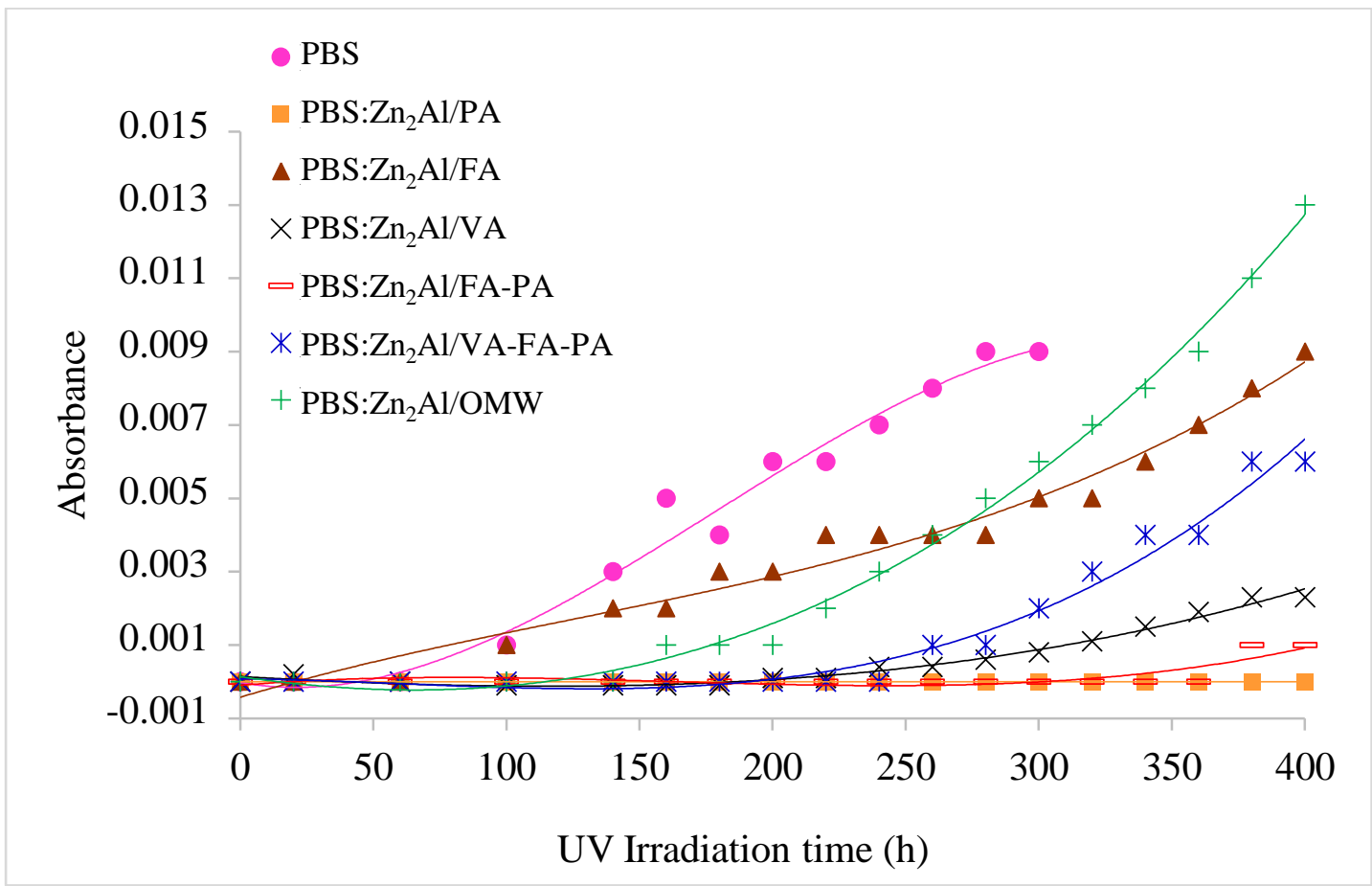

Figure 9: Kinetic curves of hydroxylated photo-products from oxidation of PBS (the film was destroyed after $300 \mathrm{~h}$ ) and its composites: evolution of hydroxyl absorbance at $3260 \mathrm{~cm}^{-1}$ as a function of photoageing time at $\lambda>300 \mathrm{~nm}$ at $60^{\circ} \mathrm{C}$. 


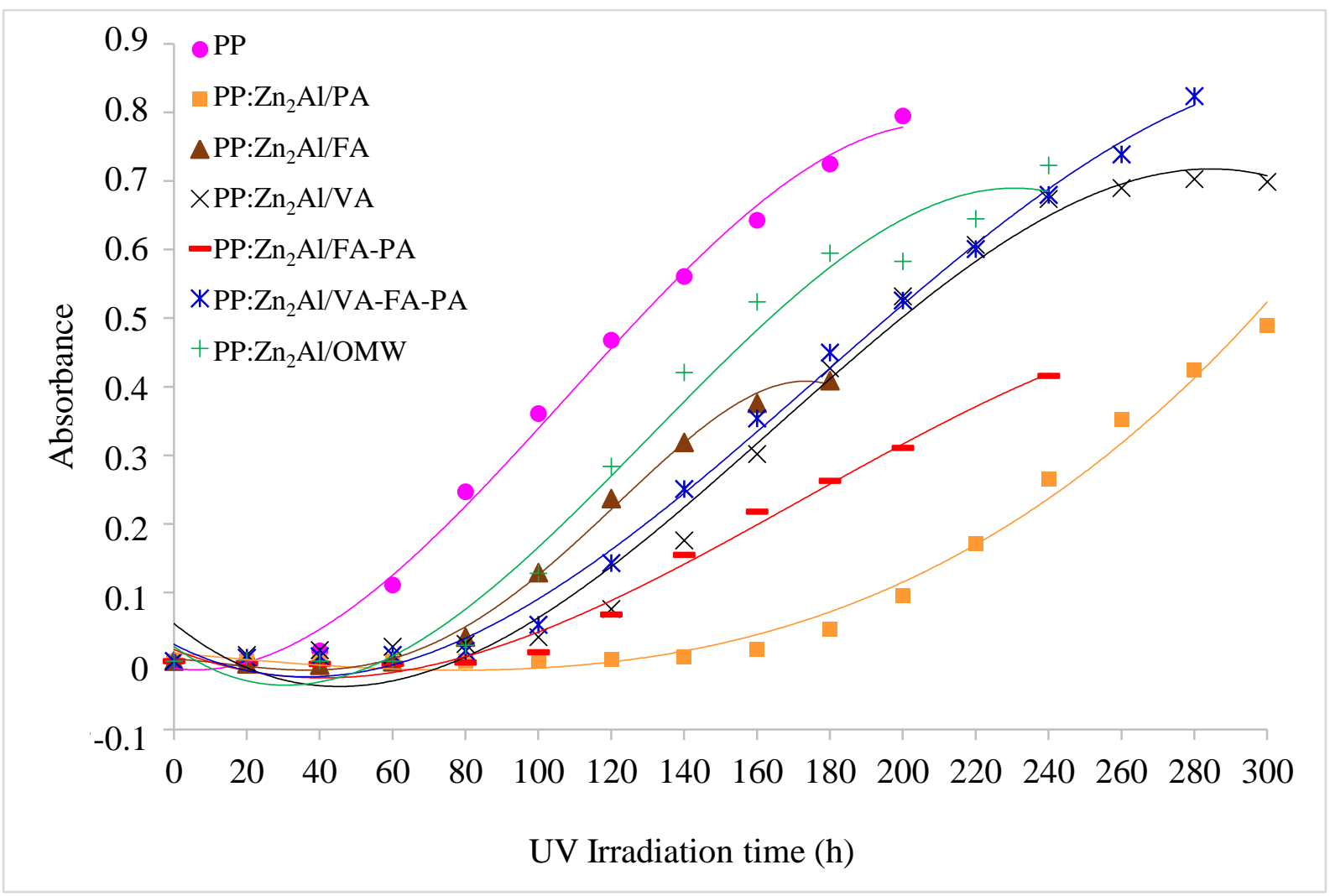

Figure 10: Kinetic curves of hydroxylated photo-products from oxidation of PP (the film was destroyed after $200 \mathrm{~h}$ ) and its composites: evolution of carbonyl absorbance at $1712 \mathrm{~cm}^{-1}$ as a function of photoageing time at $\lambda>300 \mathrm{~nm}$ at $60^{\circ} \mathrm{C}$.

\section{Conclusion}

This work demonstrates the possibility of exploiting the olive mill wastewater, without any pre-treatment, in multifunctional polymeric composites, through intercalation into a ZnAlLDH. To confirm the success of this strategy, some LDHs with model molecules, chosen among those present in OMW, such as vanillic acid, protocatechuic acid and trans-ferulic acid, were also prepared.

It is notable that the organo-modification occurred in all the series of hybrid LDHs. The PP composites result in having higher thermal stability as compared to the virgin PP polymer. All the LDHs prepared proved to be effective in protecting the polymer matrices against oxidation and thermal decomposition. Therefore olive mill wastewater, whose management is a big issue in Mediterranean countries, finds here a new and simple valorization route, improving the durability of both PBS and PP polymers.

Such strategy offers great advantages since the biowaste was used without any pretreatment, thus avoiding the high processing costs required by the common extraction 
procedures necessary to recover biomolecules from OMW. Also, considering that improper disposal can cause pollution, a further bioremediation step can be prevented.

Moreover, a further optimization of OMW valorization could be obtained through the isolation of $\mathrm{PA}$, the main constituent of OMW, that contributes to a stronger protection against UV radiation, improving the antioxidant properties of the final material.

Furthermore, since such hybrid materials are potentially exploitable for active packaging application, mechanical and antibacterial properties will be investigated in a future work.

\section{Acknowledgements}

The authors wish to thank Prof. Lorenzo Bertin for providing OMW and Dr. Maura Ferri for HPLC analysis.

\section{References}

1. Arancon, R. A. D.; Lin, C. S. K.; Chan, K. M.; Kwan, T. H.; Luque, R. Advances on waste valorization: new horizons for a more sustainable society, Energy Sci. Eng., 2013, 1, 53-71.

2. Yakhlef, W.; Arhab, R.; Romero, C.; Brenes, M.; de Castro, A.; Medina, E. Phenolic composition and antimicrobial activity of Algerian olive products and by-products, LWT, 2018, 93, 323-328

3. Chatzistathis, T.; Koutsos T. Olive mill wastewater as a source of organic matter, water and nutrients for restoration of degraded soils and for crops managed with sustainable systems, Agricultural Water Management, 2017, 190, 55-64

4. Goula, A. M.; Lazarides, H. N. Integrated processes can turn industrial food waste into valuable food by-products and/or ingredients: The cases of olive mill and pomegranate wastes, J. Food Eng. 2015, 167, 45-50.

5. Tafesh, A.; Najami, N.; Jadoun, J.; Halahlih, F.; Riepl, H.; Azaizeh, H. Synergistic Antibacterial Effects of Polyphenolic Compounds from Olive Mill Wastewater, Evidence-Based Complementary and Alternative Medicine, 2011, 431021, 9 pages.

6. Sakhel, S. R.; Geissen, S-U.; Vogelpohl, A. Virtual industrial water usage and wastewater generation in the Middle East and North Africa 2011-2015. Euro-Mediterr J Environ Integr, 2017, 2, 7-18.

7. El-Abbassi, A.; Saadaoui, N.; Kiai, H.; Raiti, J.; Hafidi, A. Potential applications of olive mill wastewater as biopesticide for crops protection, Sci. Total Environ., 2017, 576, 10-21. 
8. Bazzarelli, F.; Piacentini, E.; Poerio, T.; Mazzei, R.; Cassano, A.; Giorno, L.; Advances in membrane operations for water purification and biophenols recovery/valorization from OMWWs, J. Memb. Sci., 2016, 497, 402-409.

9. Chakraborty, S.; Drioli, E.; Giorno, L. Development of a two separate phase submerged biocatalytic membrane reactor for the production of fatty acids and glycerol from residual vegetable oil streams, Biomass and bioenergy 2012, 46, 574-583.

10. Chakraborty, S.; Rusli, H.; Nath, A.; Sikder, J.; Bhattacharjee, C.; Curcio, S.; Drioli, E. Immobilized biocatalytic process development and potential application in membrane separation: a review. Crit Rev Biotechnol. 2016, 36, 43-58.

11. Scoma, A.; Pintucci, C.; Bertin, L.; Carlozzi, P.; Fava, F. Increasing the large scale feasibility of a solid phase extraction procedure for the recovery of natural antioxidants from olive mill wastewaters, Chem. Eng. J., 2012, 198-199, 103-109.

12. Leroux, F.; Dalod, A.; Hennous, M.; Sisti, L.; Totaro, G.; Celli, A.; Coelho, C.; Verney, V. X-ray diffraction and rheology cross-study of polymer chain penetrating surfactant tethered layered double hydroxide resulting into intermixed structure with polypropylene, poly(butylene)succinate and poly(dimethyl)siloxane, Appl. Clay Sci., 2014, 100, 102-111.

13. Hennous, M.; Derriche, Z.; Privas, E.; Navard, P.; Verney, V.; Leroux, F. Lignosulfonate interleaved layered double hydroxide: A novel green organoclay for bio-related polymer, Appl. Clay Sci., 2013, 71, 42-48.

14. Sisti, L.; Totaro, G.; Fiorini, M.; Celli, A.; Coelho, C.; Hennous, M.; Verney, V.; Leroux, F. Poly(butylene succinate)/layered double hydroxide bionanocomposites: Relationships between chemical structure of LDH anion, delamination strategy, and final properties, J. Appl. Polym. Sci., 2013, 130, 1931-1940.

15. Coelho, C.; Stimpfling, T.; Leroux, F.; Verney, V. Inorganic-Organic Hybrid Materials Based on Amino Acid Modified Hydrotalcites Used as UV-Absorber Fillers for Polybutylene Succinate, Europ. J. Inorg. Chem., 2012, 2012, 5252-5258.

16. Totaro, G.; Sisti, L.; Celli, A.; Hennous, M.; Askanian, H.; Verney, V.; Leroux, F. Chain extender effect of 3-(4-hydroxyphenyl)propionic acid/layered double hydroxide in PBS bionanocomposites, Europ. Polym. J. 2017, 94, 20-32.

17. Totaro, G.; Sisti, L.; Celli, A.; Askanian, H.; Verney, V.; Leroux, F. Poly(butylene succinate) bionanocomposites: a novel bio-organo-modified layered double hydroxide for superior mechanical properties, $R S C A d v$., 2016, 6, 4780-4791. 
18. Mosangi, D.; Moyo, L.; Pillai, S. K.; Sinha Ray, S. Acetyl salicylic acid-ZnAl layered double hydroxide functional nanohybrid for skin care application, $R S C A d v$., 2016, 6, 105862-105870.

19. Rossi, C.; Schoubben, A.; Ricci, M.; Perioli, L.; Ambrogi, V.; Latterini, L.; Aloisi, G. G.; Rossi, A. Intercalation of the radical scavenger ferulic acid in hydrotalcite-like anionic clays, Int. J. Pharm., 2005, 295, 47-55.

20. Yamada, H.; Tamura, K.; Watanabe, Y.; Iyi, N.; Morimoto, K. Geomaterials: their application to environmental remediation, Sci. Technol. Adv. Mater., 2011, 12, 064705 (13pp).

21. Privas, E.; Leroux, F.; Navard, P. Preparation and properties of blends composed of lignosulfonated layered double hydroxide/plasticized starch and thermoplastics, Carbohydr. Polym., 2013, 96, 91-100.

22. Thompson, C.; Bravo Cordero, M. L.; O'Hare, D. M. Layered double hydroxides US20170202978 A1.

23. Marek, A.; Verney, V. Rheological behavior of polyolefins during UV irradiation at high temperature as a coupled degradative process, Europ. Polym. J., 2015, 72, 1-11.

24. Diouf-Lewis, A.; Commereuc, S.; Verney, V. Toward greener polyolefins: Antioxidant effect of phytic acid from cereal waste, Europ. Polym. J., 2017, 96, 190-199.

25. Sisti, L.; Totaro, G.; Marchese, P. PBS Makes its Entrance into the Family of Biobased Plastics, in book: Biodegradable and Biobased Polymers for Environmental and Biomedical Applications, Publisher: Scrivener Publishing, Wiley, Editors: Susheel Kalia, Luc Averous, Feb 2016, Chapter 7, pp.225-273.

26. Kirschweng, B.; Tátraaljaia, D.; Földes, E.; Pukánszky, B. Natural antioxidants as stabilizers for polymers, Polymer Degradation and Stability (2017) 145, 25-40]

27. Arrigo, R.; Dintcheva, N. T. Natural anti-oxidant for Bio-polymeric Materials, Arch Chem Res., 2017, 1:2.

28. Totaro, G.; Sisti, L.; Celli, A.; Aloisio, I.; Di Gioia, D.; Marek, A.; Verney, V.; Leroux, F. Dual chain extension effect and antibacterial properties of biomolecules interleaved within LDH dispersed into PBS by in situ polymerization, Dalton Trans., 2018, 47, 3155-3165.

29. Gao, Y.; Wang, Q.; Wang, J.; Huang, L.; X.; Yan, Zhang, X.; He, Q.; Xing, Z.; Guo, Z. Synthesis of Highly Efficient Flame Retardant High-Density Polyethylene Nanocomposites with Inorgano-Layered Double Hydroxides As Nanofiller Using Solvent Mixing Method, ACS Appl Mater Interfaces 2014, 6, 5094-5104. 
30. Lemaire, J.; Arnaud, R.; Lacoste, J. The prediction of the long-term photoageing of solid polymers, Acta Polym., 1988, 39, 27-32.

31. Lemaire, J.; Arnaud, R.; Gardette, J. L.; Lacoste, J.; Seinera, H. Zuverlässigkeit der methode der photo-schnellalterung bei polymeren. Kunststoffe, Ger. Plast., 1986, 76, $149-153$.

32. Kim, H-J.; Ryu, K.; Kang, J-H.; Choi, A-J.; Kim, T-i.; Oh, J-M. Anticancer Activity of Ferulic Acid-Inorganic Nanohybrids Synthesized via Two Different Hybridization Routes, Reconstruction and Exfoliation-Reassembly, The Scientific World Journal, 2013, 2013, 421967 (9pp).

33. Nara, M.; Torii, H.; Tasumi, M. Correlation between the Vibrational Frequencies of the Carboxylate Group and the Types of Its Coordination to a Metal Ion: An ab Initio Molecular Orbital Study, J. Phys. Chem., 1996, 100, 19812-19817.

34. Silion, M.; Hritcu, D.; Lisa, G.; Popa, M. I. New hybrid materials based on layered double hydroxides and antioxidant compounds. Preparation, characterization and release kinetic studies, J. Porous Mater., 2012, 19, 267-276.

35. Kang, H.; Kim, H-J.; Yang, J-H.; Kim, T-H.; Choi, G.; Paek, S-M.; Choi, A-J.; Choy, J-H.; Oh, J-M. Intracrystalline structure and release pattern of ferulic acid intercalated into layered double hydroxide through various synthesis routes, Appl. Clay Sci., 2015, 112-113, 32-39.

36. Stimpfling, T.; Leroux, F.; Hintze-Bruening, H. Organo-modified layered double hydroxide in coating formulation to protect AA2024 from corrosion, Colloids and Surfaces A: Physicochem. Eng. Aspects, 2014, 458, 147-154.

37. Yang, Y.; Zhao, X.; Zhu, Y.; Zhang, F. Transformation Mechanism of Magnesium and Aluminum Precursor Solution into Crystallites of Layered Double Hydroxide, Chemistry of Materials, 2012, 24, 81-87.

38. Coelho, C.; Hennous, M.; Verney, V.; Leroux, F. Functionalisation of polybutylene succinate nanocomposites: from structure to reinforcement of UV-absorbing and mechanical properties, $R S C A d v$., 2012, 2, 5430-5438.

39. Ichikawa, Y.; Kondo, H.; Igarashi, Y.; Noguchi, K.; Okuyama, K.; Washiyama, J. Crystal structures of $\alpha$ and $\beta$ forms of poly(tetramethylene succinate), Polymer, 2000, 41, 4719-4727.

40. Wang, X.; Zhou, J.; Li, L. Multiple melting behavior of poly(butylene succinate), Europ. Polym. J., 2007, 43, 3163-3170. 
41. Auriemma, F.; De Rosa, C. Stretching Isotactic Polypropylene: From "cross- $\beta$ " to Crosshatches, from $\gamma$ Form to $\alpha$ Form, Macromolecules, 2006, 39, 7635-7647.

42. Moyo, L.; Sinha Ray, S.; Sebati, W.; Ojijo, V. The influence of filler surface modification on mechanical and material properties of layered double hydroxide-containing polypropylene composites, J. Appl. Polym. Sci., 2017, 134, 45024(1-14).

43. Obadal, M.; Čermák, R.; Raab, M.; Verney, V.; Commereuc, S.; Fraïsse, F. Structure evolution of $\alpha$ - and $\beta$-polypropylenes upon UV irradiation: A multiscale comparison, Polym. Degrad. Stab., 2003, 88, 532-539.

44. Shi, Y.; Chen, F.; Yang, J.; Zhong, M. Crystallinity and thermal stability of LDH/polypropylene nanocomposites, Appl. Clay Sci., 2010, 20, 87-91.

45. Wang, L.; Zhang, M.; Zhou, B. Thermal Stability, Combustion Behavior, and Mechanical Property in a Flame-Retardant Polypropylene System, Appl. Sci., 2017, 7, $55(3-12)$.

46. Carroccio, S.; Rizzarelli, P.; Puglisi, C.; Montaudo, G. MALDI Investigation of Photooxidation in Aliphatic Polyesters: Poly(butylene succinate), Macromolecules, 2004, 37, 6576-6586.

47. Totaro, G.; Marchese, P.; Banella, M. B.; Sisti, L.; Celli, A.; Verney, V.; Commereuc, S. Ageing of PCCD aliphatic polyesters: Effect of stereochemistry andionic chain terminals, J. Photochem. Photobiol. A, 2014, 292, 42-48.

48. Sullalti, S.; Totaro, G.; Haskanian, H.; Celli, A.; Marchese, P.; Verney, V.; Commereuc, S. Photodegradation of $\mathrm{TiO}_{2}$ composites based on polyesters, $J$. Photochem. Photobiol. A, 2016, 321, 275-283.

49. Morlat, S.; Mailhot, B.; Gonzalez, D.; Gardette J-L. Photo-oxidation of Polypropylene/Montmorillonite Nanocomposites. 1. Influence of Nanoclay and Compatibilizing Agent, Chem. Mater., 2004, 16, 377-383.

\section{ELECTRONIC SUPPLEMENTARY INFO}

A new valorization route for Olive Mill Wastewater: Improvement of durability of PP and PBS composites through multifunctional hybrid systems.

Laura Sisti ${ }^{1}$, Grazia Totaro ${ }^{1 *}$, Annamaria Celli ${ }^{1}$, Audrey Diouf-Lewis ${ }^{2}$, Vincent Verney ${ }^{2}$, Fabrice Leroux ${ }^{2}$ 
${ }^{l}$ Dipartimento di Ingegneria Civile, Chimica, Ambientale e dei Materiali, Università di Bologna, Via Terracini 28, 40131 Bologna, Italy ${ }^{2}$ Institut de Chimie de Clermont Ferrand (ICCF) - UMR, CNRS, SIGMA Clermont, 6296 Université Clermont Auvergne, 24 Avenue Blaise Pascal, 63177 AUBIERE (cedex), France

*Corresponding Author: Grazia Totaro, grazia.totaro@unibo.it

TGA thermograms, related to the nanocomposites prepared, are reported in Figures S1S2, The thermal data are reported in Table 3 of the main text.

PBS and its composites lose weight in one main decomposition step in the range 360$375^{\circ} \mathrm{C}$. The thermal stability of PBS, is not improved by LDH. The nanocomposites are characterized by $\mathrm{T}_{\text {onset }}$ and $\mathrm{T}^{50} \mathrm{D}$ always located at lower temperatures than that of PBS. This is attributed to the presence of metals, that can catalyze the intermolecular and intramolecular transesterifications of the polyesters, or to accelerated chain hydrolysis arising from water released from the decomposed LDH. In any case the degradation temperatures are consistently higher than the melting temperatures of PBS and the relative composites: therefore, it is expected that polymer processing occurs without degradation problems. The residues are almost consistent with the charge loading.

On the other hand, LDH improves the thermal stability of PP, as observed by TGA curves (Figure $\mathrm{S} 2$ ) and $\mathrm{T}_{\text {onset }}$ and $\mathrm{T}^{50}{ }_{\mathrm{D}}$ values (Table 3, main text). In particular, $\mathrm{T}^{50}{ }_{\mathrm{D}}$ values are higher respect to $\mathrm{PP}$ (e.g. $363^{\circ} \mathrm{C}$ for $\mathrm{PP}: \mathrm{Zn}_{2} \mathrm{Al} / \mathrm{PA}$ respect to $336{ }^{\circ} \mathrm{C}$ for $\mathrm{PP}$ ). During combustion, LDHs lose interlayer water and intercalated anions, and they dehydroxylate to a mixed metal oxide. These processes absorb large amounts of heat, diluting the concentration of oxygen and hence working as a heat sink. Additionally, the formation of metal oxides contributes to the creation of char, which ultimately forms a barrier against heat and mass transfer.

Figure S1. TGA profiles of PBS and its composites. 


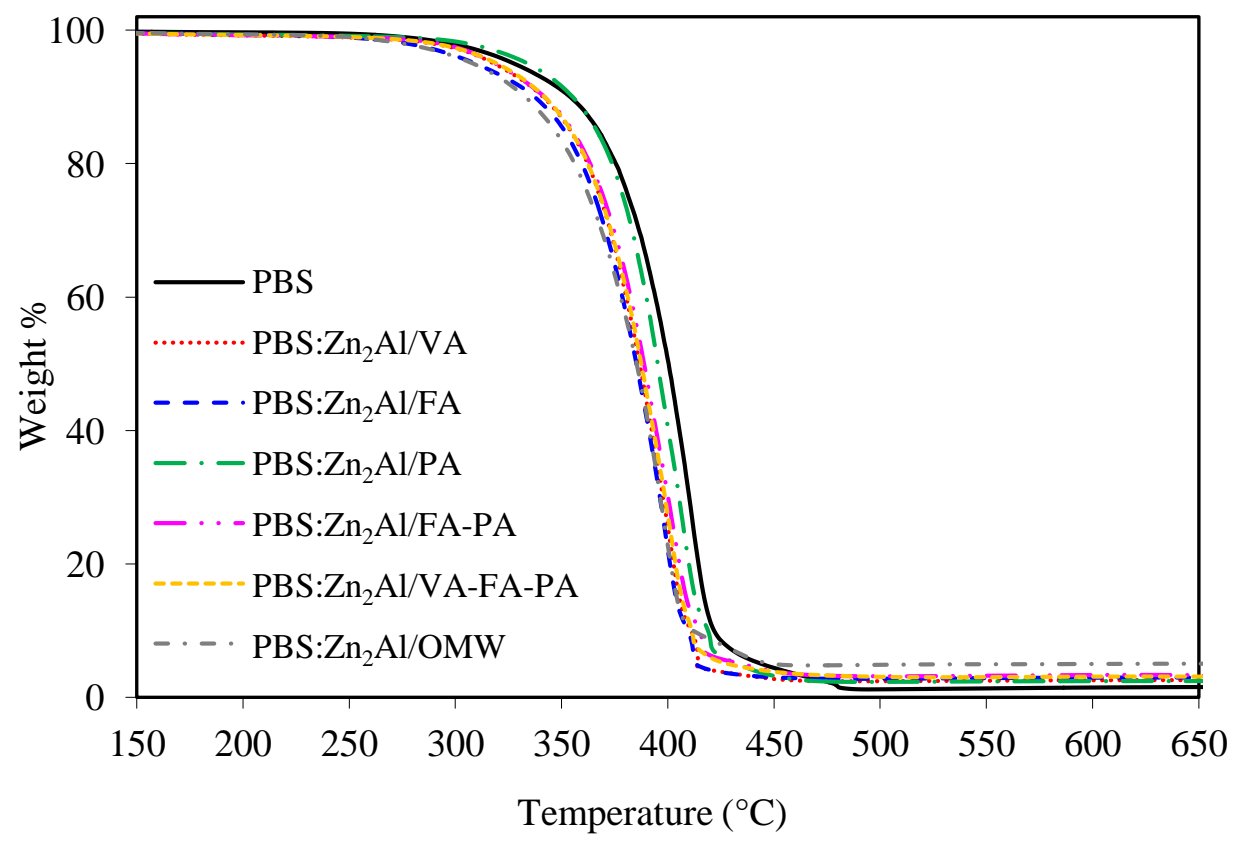

Figure S2. TGA profiles of PP and its composites.

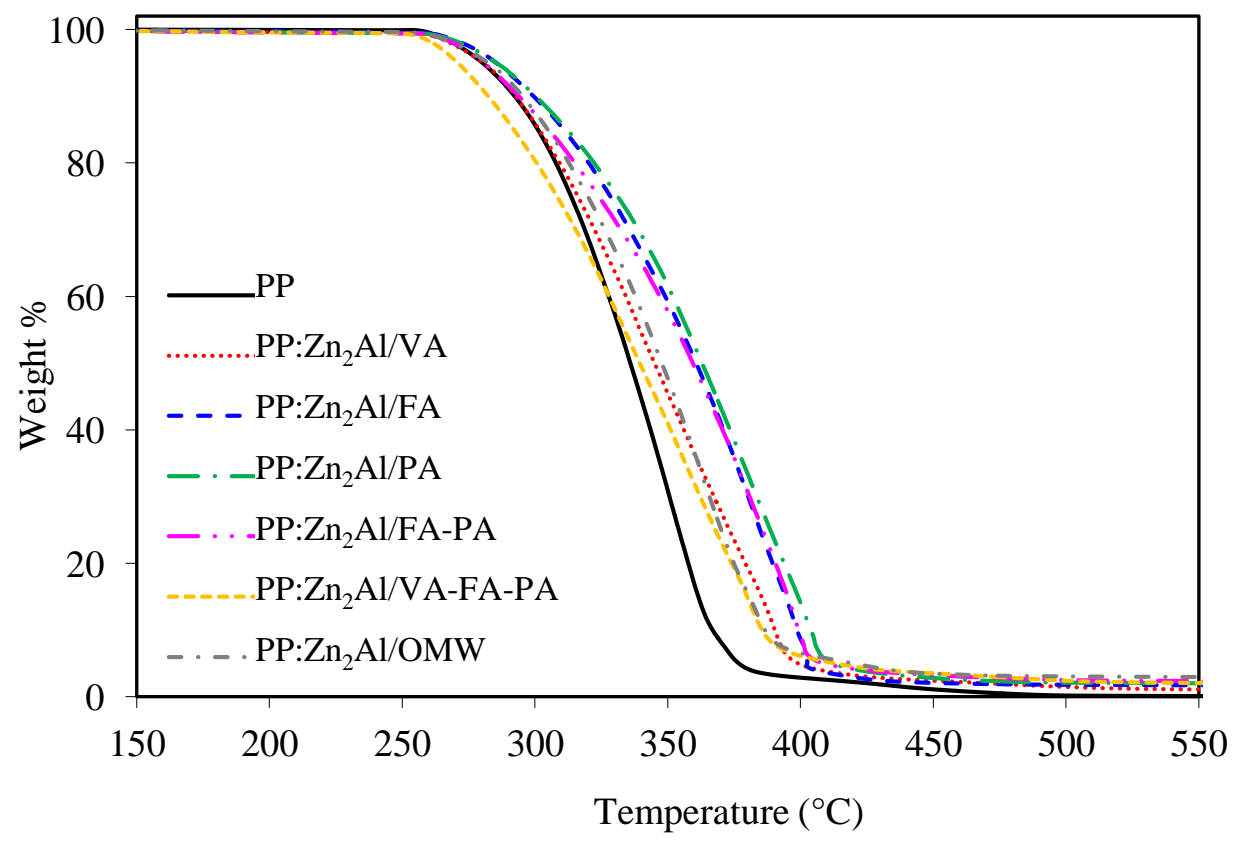

